\title{
Fungiform Papilla Pattern: EGF Regulates Inter-Papilla Lingual Epithelium and Decreases Papilla Number by Means of PI3K/ Akt, MEK/ERK, and p38 MAPK Signaling
}

\author{
Hong-Xiang Liu, ${ }^{1}$ Bradley S. Henson, ${ }^{2 \dagger}$ Yanqiu Zhou, ${ }^{1}$ Nisha J. D’Silva, ${ }^{3}$ and Charlotte M. Mistretta ${ }^{1 *}$
}

Fungiform papillae are epithelial taste organs that form on the tongue, requiring differentiation of papillae and inter-papilla epithelium. We tested roles of epidermal growth factor (EGF) and the receptor EGFR in papilla development. Developmentally, EGF was localized within and between papillae whereas EGFR was progressively restricted to inter-papilla epithelium. In tongue cultures, EGF decreased papillae and increased cell proliferation in inter-papilla epithelium in a concentration-dependent manner, whereas EGFR inhibitor increased and fused papillae. EGF preincubation could over-ride disruption of Shh signaling that ordinarily would effect a doubling of fungiform papillae. With EGF-induced activation of EGFR, we demonstrated phosphorylation in PI3K/Akt, MEK/ERK, and p38 MAPK pathways; with pathway inhibitors (LY294002, U0126, SB203580) the EGF-mediated decrease in papillae was reversed, and synergistic actions were shown. Thus, EGF/EGFR signaling by means of PI3K/Akt, MEK/ERK, and p38 MAPK contributes to epithelial cell proliferation between papillae; this biases against papilla differentiation and reduces numbers of papillae. Developmental Dynamics 237:2378-2393, 2008. $\odot 2008$ Wiley-Liss, Inc.

Key words: taste papilla; fungiform papilla; EGF/EGFR signaling; PI3K/Akt; MEK/ERK; p38 MAP Kinase; tongue epithelium

Accepted 9 June 2008

\section{INTRODUCTION}

Taste papilla development and patterning require interactive programs both for induction of the specific organ and differentiation of inter-papilla epithelium (Mistretta and Liu, 2006). Whereas the development of fungiform papillae in their distinctive pattern has long been noted (Mistretta, 1972, 1998; Mbiene et al., 1997), there is not a clear understanding of molecular events in papilla patterning. EGF is a potent secreted factor that has reported roles in spacing other epithelial specializations including hair (Mak and Chan, 2003), feather (Atit et al., 2003), and denticle (Urban et al., 2004), but potential regulatory roles for EGF in fungiform papilla patterning have not been studied. Therefore, distinctions or developmental generalizations between EGF actions in skin vs. lingual specialized organs are not known. Here, we demonstrate roles of
EGF and EGFR in defining the interpapilla space in embryonic rat tongue; report EGF effects in lingual epithelial cell proliferation; and, identify intracellular signaling pathways that mediate EGF effects.

The mammalian tongue hosts three types of taste papillae: fungiform, circumvallate, and foliate, each with a unique location, morphology, and innervation to resident taste buds. Fungiform papillae develop in diagonal

\footnotetext{
${ }^{1}$ Department of Biologic and Materials Sciences, School of Dentistry, University of Michigan, Ann Arbor, Michigan

${ }^{2}$ Oral Health Sciences Ph.D. Program, School of Dentistry, University of Michigan, Ann Arbor, Michigan

${ }^{3}$ Department of Periodontics and Oral Medicine, School of Dentistry, and Department of Pathology, Medical School, University of Michigan,

Ann Arbor, Michigan

Grant sponsor: NIDCD, NIH; Grant number: DC000456.

†Dr. Henson's present address is School of Dentistry, University of California, Los Angeles, CA

*Correspondence to: Charlotte M. Mistretta, Room 6217, School of Dentistry, University of Michigan, Ann Arbor, MI 481091078. E-mail: chmist@umich.edu
}

DOI 10.1002/dvdy.21657

Published online 26 August 2008 in Wiley InterScience (www.interscience.wiley.com). 
rows on the anterior two-thirds of the rodent tongue, from a homogeneous epithelium that covers the three lingual swellings at embryonic day (E) 13 in rat (Mistretta, 1972, 1991; Mbiene et al., 1997) or E11.5-E12 in mouse (Kaufman, 1992). Approximately 1 day later, E14, when lingual swellings have merged into a spatulate tongue, papilla placodes are first identified as focal cell clusters. By E15, the tongue has a distinctive topography and fungiform papillae are in rows on anterior tongue (Mistretta, 1972; Mbiene et al., 1997). The nontaste, heavily keratinized filiform papillae that cover interpapilla epithelium in the postnatal tongue are not visible until approximately E20. Furthermore, histologically defined, early taste buds are not seen in rodent papillae until just before birth; taste bud development is essentially postnatal (Mistretta, 1991; Hill, 2001).

Functional roles are known for Sonic hedgehog (SHH; Hall et al., 2003; Mistretta et al., 2003; Liu et al., 2004); bone morphogenetic protein (BMP) 2, 4, and 7 and NOGGIN (Zhou et al., 2006); SOX2 (Okubo et al., 2006); and WNT10b (Iwatsuki et al., 2007; Liu et al., 2007) in regulating the number and distribution of fungiform papillae. These factors have stage-specific effects and can induce or inhibit papilla development. However, in these studies there has not been attention to the inter-papilla epithelium and in fact, little is known about regulation of inter-papilla epithelial differentiation in patterning. There are specific innervation patterns to taste papillae compared with inter-papilla, nontaste epithelium (Mistretta, 1998; Hill, 2001). Therefore, to understand development of sensory functions, it is important to know how differentiation programs arise for gustatory organs vs. filiform papilla domains. EGF has prominent roles in cell survival, proliferation, and differentiation (Woodburn, 1999; Harris et al., 2003; Shilo, 2005), and, therefore, could have dual functions in papilla and inter-papilla epithelial development.

Aberrant morphology in surviving, EGFR null mutant mice previously suggested a role for EGF in fungiform papilla development (Miettinen et al., 1995; Threadgill et al., 1995; Sun and Oakley, 2002). However, the mice had compromised face and tongue integ- rity that limited conclusions about EGF effects on papillae. In organ culture, there is a unique opportunity for direct study of tongue and taste papilla development in a quantitative manner, without confounding effects from oral-facial deformities. The entire tongue progresses from three lingual swellings (at E13) to a spatulate (E14) and larger (E15-E16) tongue, and taste papillae form with retention of spatial, temporal, and molecular information that is similar to in vivo development (Mbiene et al., 1997; Nosrat et al., 2001; Liu et al., 2004). This culture system now is widely used to understand papilla development (Hall et al., 2003; Mistretta et al., 2003; Okubo et al., 2006; Zhou et al., 2006; Iwatsuki et al., 2007).

In the present study, we first identify specific EGF and EGFR locations during tongue and papilla development. Then, we investigate EGF effects in tongue cultures begun at two early embryonic stages, when tongue epithelium is homogenous and not differentiated to papilla or inter-papilla fates (E13) and just after prepapilla placodes have begun to emerge (E14). We show that exogenous EGF regulates patterning by reducing papilla number, and that EGF action on fungiform papillae is mediated by means of EGFR. Furthermore, we demonstrate that EGF/EGFR action increases inter-papilla cell proliferation and can over-ride SHH signaling disruption that doubles the number of fungiform papillae. Mediating the epithelial effects, EGFR-induced intracellular signaling cascades including phosphatidylinositol 3-kinase (PI3K)/ Akt, MEK/ERK, and p38 MAPK cascades are shown to have specific roles. Together, results show new roles for EGF signaling by means of EGFR, in regulating fungiform papillae and tongue epithelium development. For the first time, specific intracellular cascades are identified in mediating papilla development.

\section{RESULTS \\ EGF and EGFR Distribute Differently in Embryonic Tongue and Papillae}

To determine spatial and temporal distributions, EGF and EGFR pro- teins were localized in E13-E18 tongues (Fig. 1, E18 not illustrated). EGF is not detected in E13, but is apparent in E14 tongue epithelium (Fig. 1, EGF-ir, arrowhead points to papilla placode at E14). At E15, EGF is in all epithelial layers in both early papilla and inter-papilla regions (Fig. 1, EGF-ir; arrow identifies fungiform papilla). Some immunostained cells are in the mesenchyme also. EGF-ir is more intense in tongue epithelium and papillae from E16 to E18 (Fig. 1, arrow points to fungiform papilla at E16).

In contrast to EGF, at E13 there already is EGFR expression in a patchy distribution in sectioned lingual epithelium, and this is more intense at E14 (Fig. 1, EGFR-ir; arrowhead identifies E14 papilla placode). At E13-E14, EGFR is localized through all layers of the epithelium.

Importantly, from E15 to E18, EGFR becomes progressively more intense in the inter-papilla space, and very weak, or not present within fungiform papilla epithelium (Fig. 1, EGFR-ir, arrows point to papillae; E18 not illustrated). No obvious immunoproducts are in the mesenchyme just beneath the epithelium.

Immunohistochemistry on E13 whole tongue echoes and clarifies the patchy distribution of EGFR-ir seen in tongue sections (Fig. 1, EGFR-ir, Whole tongue, E13). At E14, the EGFR-ir is dense along the median furrow (open arrowheads) where a row of fungiform papillae will form. Thus, in whole tongue immunoreactions, evidence for an emerging localization of EGFR in relation to papilla placode zones is apparent. In E15E16 whole tongues, EGFR is absent in developing and well formed papillae, confirming the result in tongue sections. Each papilla is delineated as a blank circle surrounded by a ring of EGFR immunoproduct (arrows at E15 and E16; inset at E16).

Thus, EGF and EGFR are in distinctive locations at specific stages during papilla development. The progressive, intense distribution of EGFR in the inter-papilla region vs. absent or very weak expression within the fungiform papillae suggests roles for EGF in regulating epithelial cell fate between papillae. 

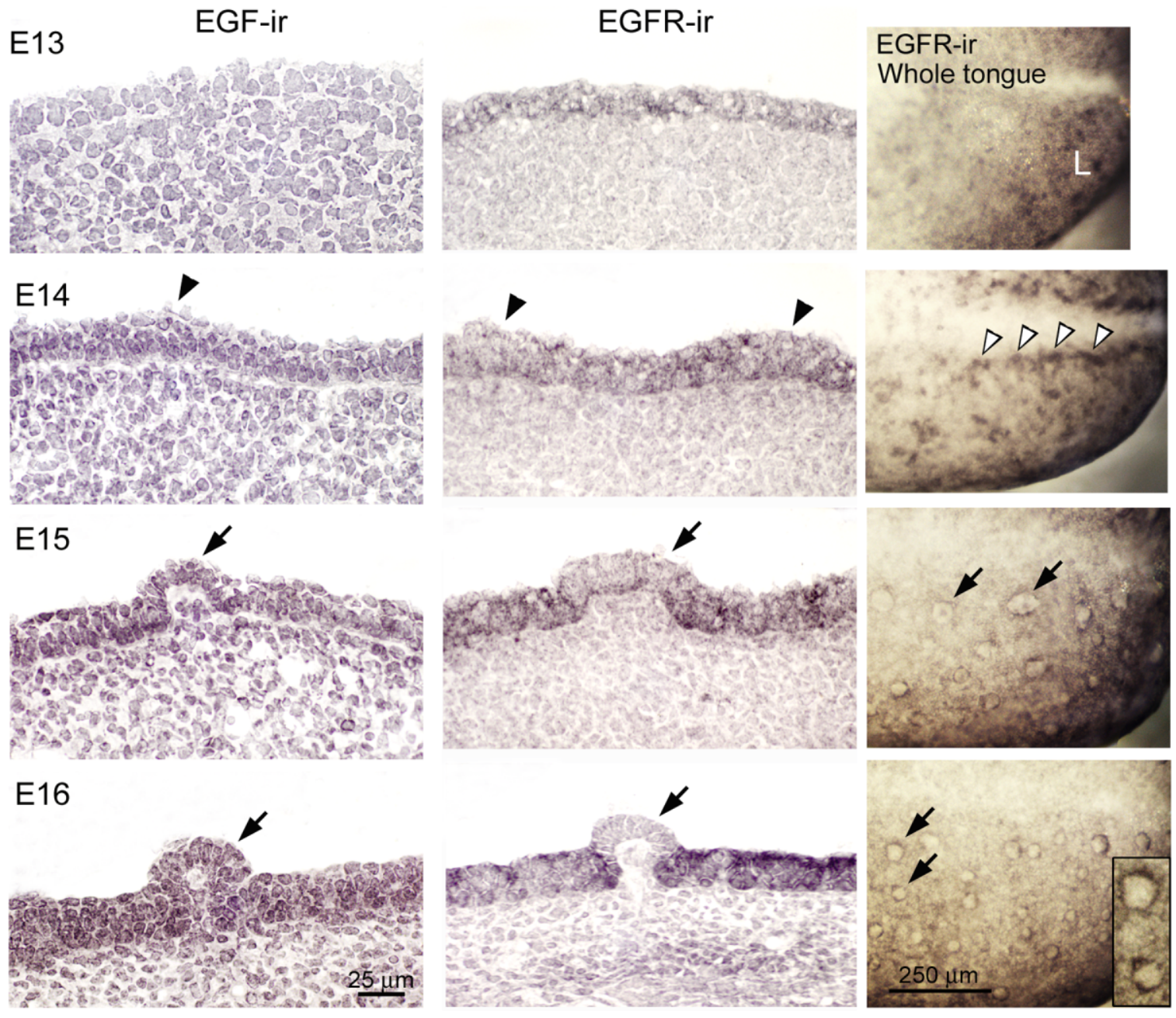

Fig. 1. Epidermal growth factor (EGF) and its receptor EGFR are in distinctive lingual distributions during fungiform papilla development. EGF and EGFR immunohistochemistry in sagittal sections and EGFR in whole tongues, embryonic day (E) 13-E16. Arrowheads point to prepapilla placodes, arrows to fungiform papillae. EGF-ir, EGF immunoreactions: EGF-ir is not apparent at E13 but is first seen in anterior tongue epithelium at E14, and becomes more intense through E16. EGF is in all layers of papilla and inter-papilla epithelium. EGFR-ir, EGFR immunoreactions: In contrast to EGF, EGFR-ir appears throughout early epithelium (E13) and has an irregular, patchy distribution in epithelium at prepapilla placode stages (E14). From E15 to E16, EGFR-ir is intense in inter-papilla epithelium, but becomes progressively weak within papillae (arrows). EGFR-ir, in Whole tongue: The anterior quarter of the tongue is illustrated. Whole tongue immunoreactions reinforce the patchy distribution of EGFR at E13-E14. At E13, EGFR-ir is intense in small patches of the anterior lingual swelling (L). At E14, in the region of prepapila placodes along the median furrow, there is intense EGFR-ir (open arrowheads). The absence of EGFR within clearly outlined fungiform papillae from E15 to E16 (arrows) is obvious. Expanded image of E16 papillae in the inset emphasizes the EGFR-free papilla apex surrounded by the receptor. Scale bars $=25 \mu \mathrm{m}$ for all tongue sections, $250 \mu \mathrm{m}$ for whole tongue.

\section{EGF Suppresses Fungiform Papilla Formation in E13 and E14 Tongue Cultures}

To test functional roles for EGF in papilla development, we used tongue cultures begun from E13 when the tongue epithelium has a homogenous surface topography that has not begun to differentiate to papilla or inter-papilla fates, and from E14 when prepapilla placodes have just begun to emerge on the tongue (Fig. 2, E13 and E14, +0 day). After 2 days in culture, fungiform papillae form on anterior tongue of E13 or E14 cultures (Fig. 2,
E13 and E14, +2 days), in numbers and location comparable to the embryonic tongue at E15 or E16 (Mbiene et al., 1997). The intermolar eminence develops and is papilla-free (Fig. 2, +2 days, IE).

Potential EGF effects in development of fungiform papillae were studied in cultures that were maintained in the control, standard medium (STAND with $0 \mathrm{ng} / \mathrm{ml}$ EGF), or with increasing concentrations of exogenous EGF, and examined with scanning microscopy and whole tongue immunoreactions for $\mathrm{SHH}$ (Fig. 3).

\section{E13 effects.}

In $\mathrm{E} 13+2$ day cultures, the three lingual swellings of the E13 tongue have grown and merged in STAND or 0 ng/ml EGF (Fig. 3A, E13 + 2 days, 0 $\mathrm{ng} / \mathrm{ml}$ EGF, scanning electron microscopy [SEM]). Numerous fungiform papillae are apparent on anterior tongue. With addition of EGF, there is a concentration-dependent decrease in fungiform papilla number in $\mathrm{E} 13+2$ day cultures (Fig. 3A, SEMs, EGF at 1-100 ng/ml). SHH immunoloci, which mark fungiform papillae (Mistretta et al., 2003), highlight this de- 
E13
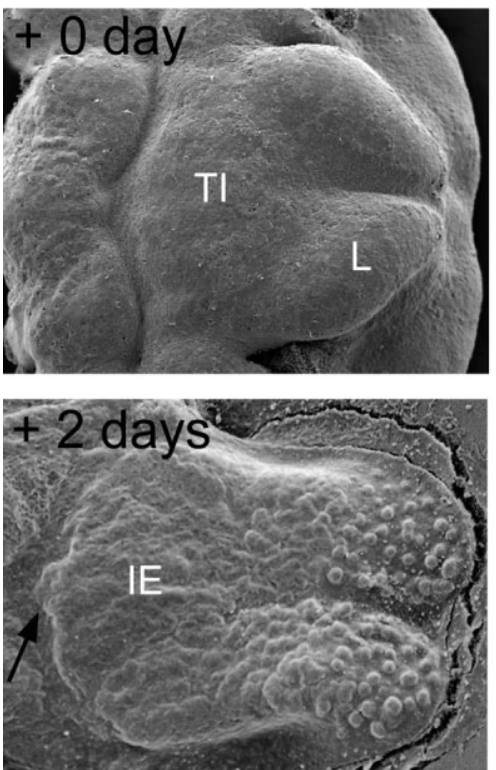

E14
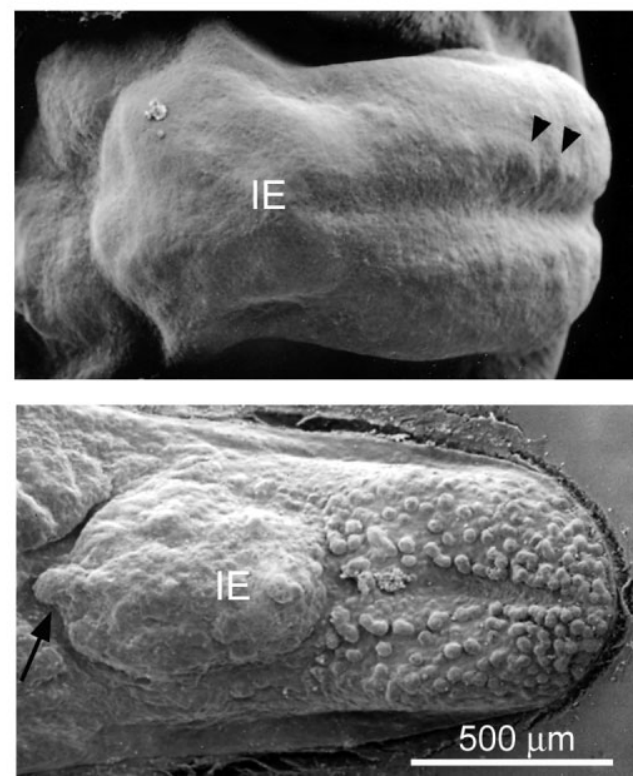

Fig. 2. Scanning electron microscope images of embryonic day (E) 13 and $E 14$ embryo tongues before and after 2 days in culture. E13: At E13 the tongue presents a homogeneous surface topography, composed of a posterior tuberculum impar (TI) and two anterior lingual swellings (L) $(E 13,+0$ day). There is no apparent differentiation of surface epithelium into prepapilla and inter-papilla regions. After dissection from the mandible and organ culture for 2 days ( +2 days), fungiform papillae form on the anterior tongue swellings and the posterior intermolar eminence (IE) is papilla-free. An arrow at the posterior border of oral tongue points to the developing circumvallate papilla. E14: Tongues at E14 have a spatulate shape with fused lingual swellings (E14, +0 day). Fungiform papillae have not yet formed, but small protuberances, the prepapilla placodes, are apparent in rows down either side of the median furrow (arrowheads). The large, papilla-free IE is seen on posterior tongue. After 2 days in culture, fungiform papillae have formed on anterior tongue ( +2 days). An arrow at the posterior tongue border points to the developing circumvallate papilla.

crease and demonstrate that remaining papillae retain $\mathrm{SHH}$ (Fig. 3A, Shhir, right column). Papillae are decreased by approximately $40 \%$ in 10 ng/ml EGF cultures compared with tongues in $0 \mathrm{ng} / \mathrm{ml}$ EGF (Fig. 3B, analysis of variance [ANOVA] $F(4,37)=$ $25.7 ; P<0.01)$. Very few papillae remain, on the tongue tip only, with 100 $\mathrm{ng} / \mathrm{ml} \mathrm{EGF}$.

\section{E14 effects.}

At E14, papilla placodes are small surface eminences (Fig. 2). Over 2 days in STAND culture with $0 \mathrm{ng} / \mathrm{ml}$ EGF, fungiform papillae develop (Fig. 3C, $\mathrm{E} 14+2$ days, $0 \mathrm{ng} / \mathrm{ml}$, SEM) and $\mathrm{SHH}$ is retained in each papilla (Fig. 3C, Shh-ir). With EGF, papilla number decreases in a concentration-dependent manner (Fig. 3C). From 3 ng/ml, there is a significant decrease in papillae and at $10 \mathrm{ng} / \mathrm{ml}$ EGF there are approximately $50 \%$ of papilla numbers observed with $0 \mathrm{ng} / \mathrm{ml}$ (Fig. 3D, ANOVA $\mathrm{F}(5,46)=42.7 ; P<0.01)$.
SHH expression in individual papillae highlights the reduction (Fig. 3C, Shh-ir).

Thus, exogenous EGF inhibits formation of fungiform papillae in embryonic tongue cultures, in a concentration-dependent manner, whether EGF is introduced before (E13) or just after (E14) prepapilla placodes appear. This means that EGF prevents formation of prepapilla placodes and thus, papillae, from E13; and, prevents differentiation of placodes to papillae from E14. The concentrationdependent effects at E13 vs. E14 suggest that EGF is more potent in promoting the inter-papilla epithelium at E14, when tongue epithelium is further committed along a dual differentiation path to taste papilla or nontaste epithelium.

We did not make a detailed study beyond the stages of placode and papilla formation in culture (begun at E13, E14). However we did observe effects of exogenous EGF at $10 \mathrm{ng} / \mathrm{ml}$ and higher concentrations in cultures begun at E15 and E17, after papillae have formed (not illustrated). The effects were apparently more pronounced on the epithelial surface than on papilla number per se, but would be interesting for further experiments.

\section{EGF Endogenous and Exogenous Effects on Papilla Formation Are Mediated by EGFR}

To determine whether EGF effects on papillae are mediated by means of EGFR, we used a potent, specific EGFR inhibitor, Compound 56 (Bridges et al., 1996), in tongue cultures. First, we demonstrated EGFR distribution with immunohistochemistry. In E14+2 day cultures, EGFR is intensely localized in all layers of dorsal epithelium in the inter-papilla space, but is very weak or absent within the papilla epithelium (Fig. 4A), similar to the distribution in E16 embryonic tongue in vivo (Fig. 1). When Compound 56 is added to STAND, to block EGFR action, the number of fungiform papillae that form is increased by $38 \%$ at $1 \mathrm{nM}$ concentration or higher (ANOVA, $F(3,15)=7.4 ; P<0.01 ;$ Bonferroni test, $P<0.05$; Fig. 4B graph). Furthermore, fungiform papillae assume fused or clustered distributions on the anterior tongue with inhibition of endogenous EGF action (compare insets in Fig. 4B, scanning microscopy images, for 0 vs. $1 \mu \mathrm{M}$ inhibitor). These fused and clustered papillae suggest actions of EGF by means of EGFR in the epithelium between papillae.

In cultures incubated with Compound 56 alone followed by concomitant use of EGF (Fig. 4C), the EGFmediated decrease in papilla number is completely reversed by $1 \mu \mathrm{M}$ or higher concentration of Compound 56 (ANOVA $F(4,19)=34.6 ; P<0.01$; Bonferroni test, $P<0.01$; Fig. $4 \mathrm{C}$ graph). Thus, the EGF effect is blocked by EGFR inhibition. A very high concentration of inhibitor (10 $\mu \mathrm{M})$ is not toxic but maintains papilla numbers at levels of STAND culture (Fig. 4C graph).

The data demonstrate that both endogenous and exogenous EGF-induced effects on fungiform papilla de- 

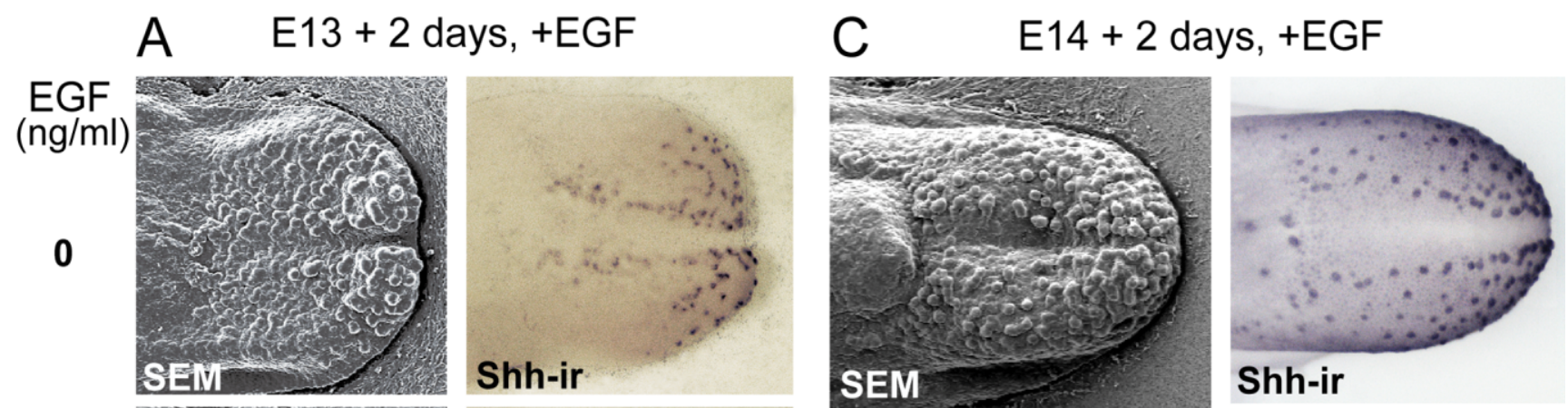

10
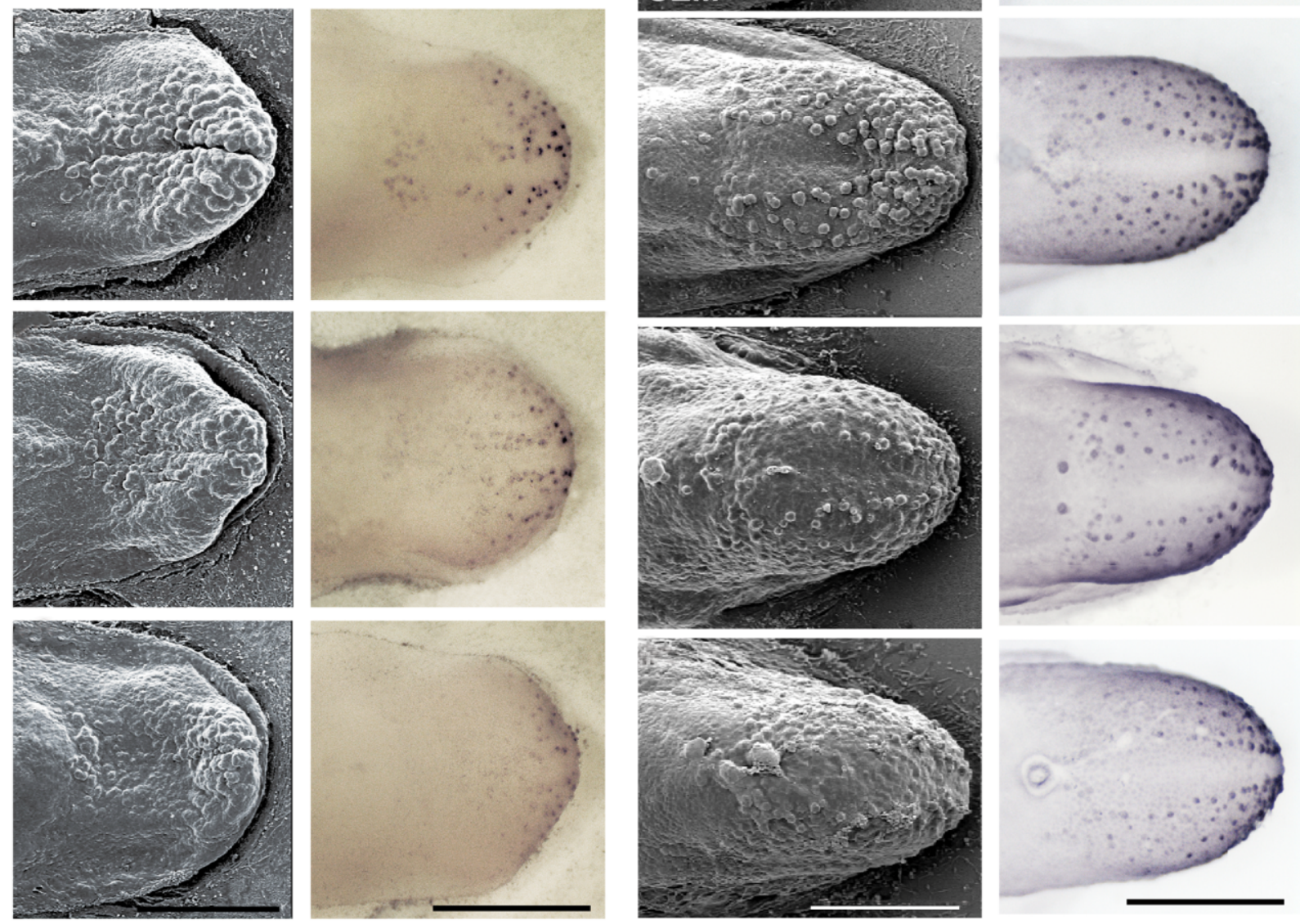

B
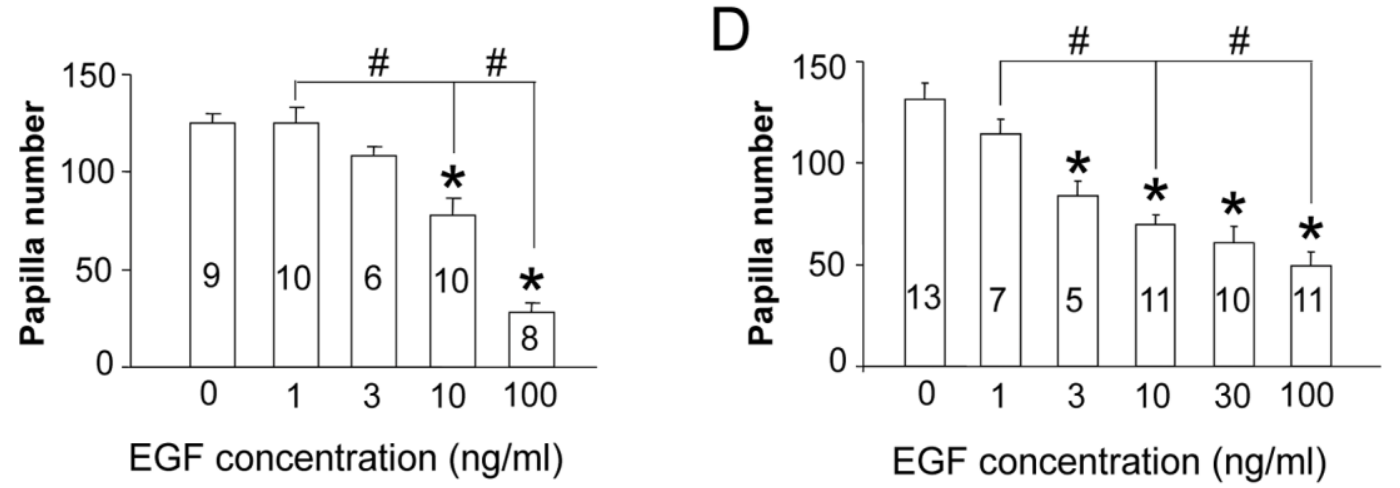

Fig. 3. Epidermal growth factor (EGF) reduces fungiform papilla number in embryonic day (E) 13 and E14 tongue cultures. A: E13 +2 day cultures: Scanning electron micrographs (SEMs, left column) and whole tongue immunoreactions for Shh (Shh-ir, right column) demonstrate a concentrationdependent decrease in papillae with 1 to $100 \mathrm{ng} / \mathrm{ml}$ EGF, compared with STAND tongue cultures (0 ng/ml EGF). At each EGF concentration, Shh-ir is retained in remaining papillae. B: Histogram of fungiform papilla number (means + SE) demonstrates a significant effect $\left(^{*}\right)$ at $10 \mathrm{ng} / \mathrm{ml}$ EGF (approximately $38 \%$ of papillae are lost) and a reduction of more than $77 \%$ with $100 \mathrm{ng} / \mathrm{ml} \mathrm{EGF,} \mathrm{compared} \mathrm{with} 0 \mathrm{ng} / \mathrm{ml}$. Also, there are significant concentration effects between $1 \mathrm{vs} 10$, and $10 \mathrm{vs} 100 \mathrm{ng} / \mathrm{ml}$ (\#). Numbers within bars are numbers of cultures in each group. C: E14 + 2 day cultures: SEMs (left) and Shh-ir (right) demonstrate a reduction in papillae when EGF is added to STAND cultures (0 $\mathrm{ng} / \mathrm{ml}$ EGF). Shh is retained in all remaining fungiform papillae (Shh-ir), at each EGF concentration. D: Papilla number (mean + SE) is decreased at 3, 10, 30, or $100 \mathrm{ng} / \mathrm{ml} \mathrm{compared} \mathrm{with} 0 \mathrm{ng} / \mathrm{ml}$ EGF (*). The reduction is by approximately $47 \%$ with $10 \mathrm{ng} / \mathrm{ml}$ EGF and by more than $64 \%$ at $100 \mathrm{ng} / \mathrm{ml}\left({ }^{*}\right.$ indicates a significant reduction from 0 concentration; \# indicates other significant, between-concentration effects). Numbers within bars are numbers of cultures in each group. Scale bars = $500 \mu \mathrm{m}$, all micrographs in A and C. 
A
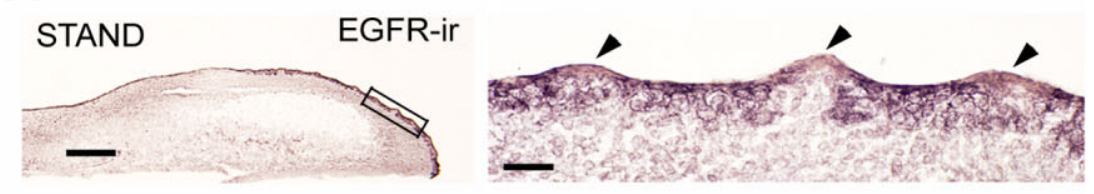

B
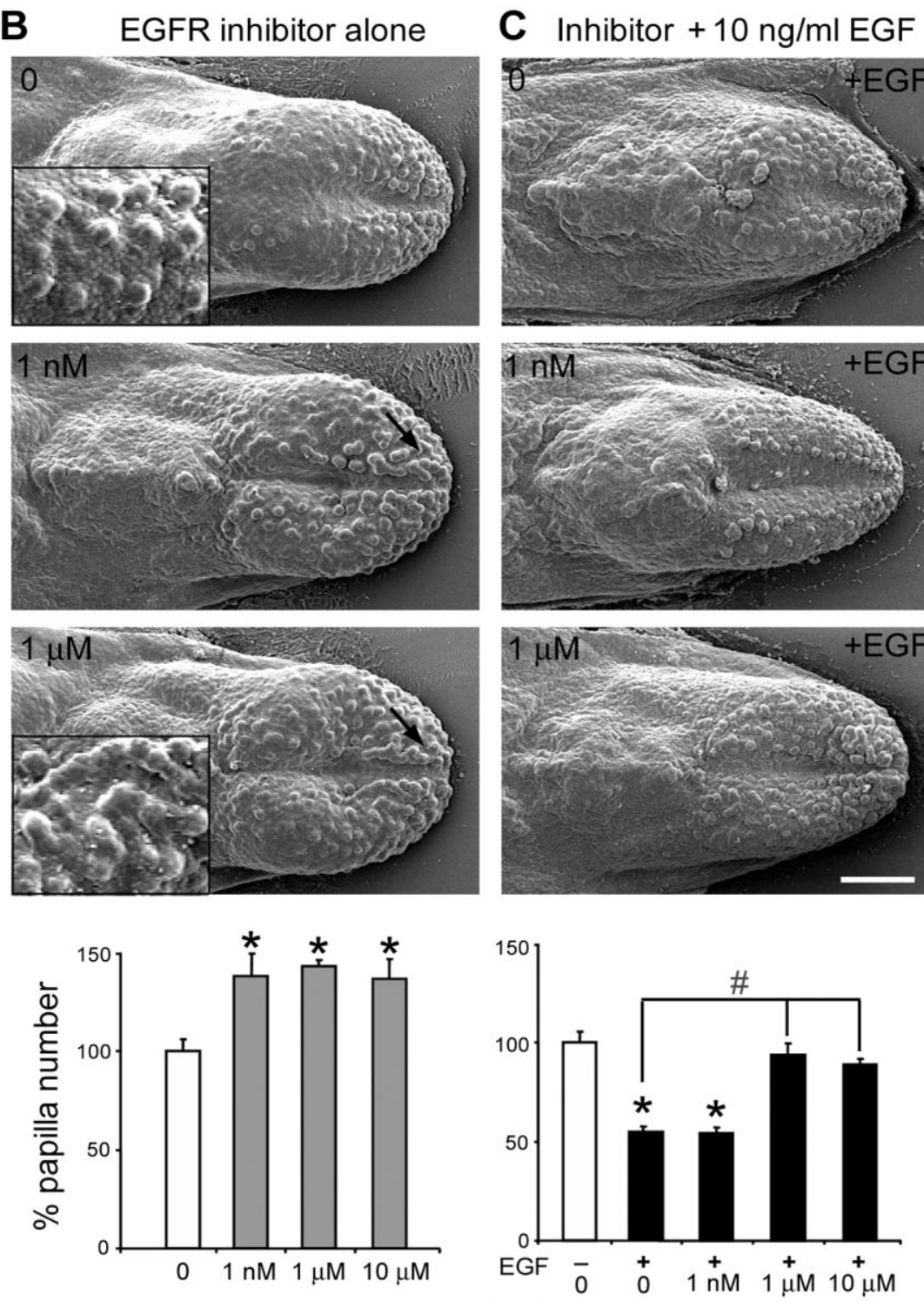

Concentration of EGFR inhibitor

Fig. 4. Epidermal growth factor receptor (EGFR) mediates the EGF effect on fungiform papillae in embryonic day (E) 14 tongue cultures. A: EGFR immunohistochemistry (EGFR-ir) in sagittal sections of E14 + 2 day STAND tongue culture. A box on the section of an entire culture encloses region of higher power image at right. EGFR is intensely localized in inter-papilla epithelium, but very weakly in the apical papilla epithelium (arrowheads). Scale bars $=250 \mu \mathrm{m}$ for section of entire culture; 50 $\mu \mathrm{m}$ for high power image. B: Scanning electron micrographs (SEMs, top) and histogram (bottom) of percentage of papilla number relative to STAND ( 0 concentration EGFR inhibitor) in tongues cultured with the EGFR inhibitor, Compound 56. Inhibition of EGFR resulted in an increase of papilla number at $1 \mathrm{nM}$ and above, and fusion of papillae (arrows in SEMs; and compare merged papillae in inset for $1 \mu \mathrm{M}$ inhibitor, to inset at 0 concentration). C: SEMs (top) and histogram (bottom) for cultures with Compound 56 inhibitor plus EGF. Compound 56, at $1 \mu \mathrm{M}$ or higher, completely reversed the EGF-induced decrease in papilla number. Cultures were incubated with Compound 56 alone for $1 \mathrm{hr}$, followed by culture with Compound 56 and exogenous EGF at $10 \mathrm{ng} / \mathrm{ml}$. Scale bar: $=250 \mu \mathrm{m}$ for all SEMs. $\left({ }^{*} P<0.05\right.$ compared with control or 0 concentration inhibitor, blank bar: ${ }^{\#} P<0.05$ compared with + EGF group without inhibitor.) velopment are mediated by means of EGFR, which is located in the interpapilla epithelium. Endogenous EGF apparently acts to sustain the interpapilla epithelium; exogenous EGF decreases papillae and promotes the inter-papilla epithelium.

\section{Exogenous EGF Increases Cell Proliferation in Lingual Epithelium Between Papillae}

Based on immunohistochemical localization and demonstrated action of EGFR, EGF must signal in the between-papilla epithelium of the tongue. To further understand sites where EGF could act during papilla development, Ki67 was used to label and compare proliferating cells in E14 and E16 tongues and in E14+2 day cultures. In the E14 tongue, Ki67-positive cells are in the epithelium between papilla placodes (Fig. 5A, E14). Within the placode epithelium (arrowhead), however, proliferating cells are absent or rare. At E16, also, the well formed fungiform papillae have no or few proliferating cells (Fig. 5A, E16, arrows). Thus, within papillae, which have reduced EGFR, there is little cell proliferation. In contrast, the epithelium between papillae, where EGFR is intense, has numerous Ki67-positive cells (Fig. 5A, E16). Ki67-labeled cells are also present in the mesenchyme at both E14 and E16, and are especially numerous at E14.

In E14+2 day cultures, there is a similar distribution of Ki67 immunoproducts. Inter-papilla cells are proliferating but Ki67 is essentially absent within the fungiform papilla epithelium (Fig. 5A, E14+2, STAND, arrows). However, with added EGF in cultures, Ki67-cells are especially numerous in the expanded inter-papilla epithelium, compared with STAND cultures (Fig. 5A, E14+2, EGF 100 $\mathrm{ng} / \mathrm{ml})$.

To quantify proliferating cells in the inter-papilla epithelium, we used Ki67 immunoreactions on sections of STAND and EGF $(10 \mathrm{ng} / \mathrm{ml})$ tongue cultures mounted on the same slides, and counted Ki67+ cells in epithelium between fungiform papillae (Fig. 5B). With exogenous EGF, there is an almost twofold increase in Ki67+ cell density in inter-papilla epithelium compared with STAND cultures. 
Thus, there are more proliferating epithelial cells between papillae in cultures with exogenous EGF. We know that EGFR also is localized to epithelium between fungiform papillae, confining EGF site of action to inter-papilla tissue. Furthermore, proliferating cells almost double in density in epithelium between papillae, when EGF is added to tongue cultures. Together, results suggest that EGF maintains inter-papilla epithelial cells in a proliferative cycle and thereby biases against differentiation to fungiform papillae.

\section{EGF Effect Can Over-ride SHH Signal Disruption}

To further explore the potency of EGF/ EGFR signaling in altering the interpapilla epithelium, we tested the ability of EGF to overcome a potent stimulus to increase papilla number. We had previously reported that, when SHH signaling is disrupted with the alkaloid cyclopamine (CYCL), fungiform papillae form in doubled numbers (Mistretta et al., 2003) and, furthermore, develop on the usually papilla-free intermolar eminence. We repeated this effect and illustrate in Figure 6 that there are 154 fungiform papillae in STAND culture compared with 418 with CYCL. Furthermore, with CYCL, fungiform papillae have formed on the intermolar eminence. To determine whether exogenous EGF can block the dramatic increase of papilla number induced by SHH disruption, we preincubated the E14 tongue with EGF and cultured the tongue for 2 days with EGF plus CYCL (Fig. 6). $\mathrm{EGF}$ at $10 \mathrm{ng} / \mathrm{ml}$ prevents the CYCLinduced papilla formation on the intermolar eminence (Fig. 6, $10 \mathrm{ng} / \mathrm{ml}$ $\mathrm{EGF}+\mathrm{CYCL}$ ) but papillae number 233 and so have increased on anterior tongue. However, with $100 \mathrm{ng} / \mathrm{ml}$ EGF, the CYCL-induced changes in papilla pattern and number are totally prevented (Fig. 6, $100 \mathrm{ng} / \mathrm{ml}$ $\mathrm{EGF}+\mathrm{CYCL}$; papilla number $=158$ ). Thus, EGF can prevent the increase in fungiform papilla number induced by interrupting $\mathrm{SHH}$ signaling, biasing against differentiation and formation of supernumerary papillae.
A E14
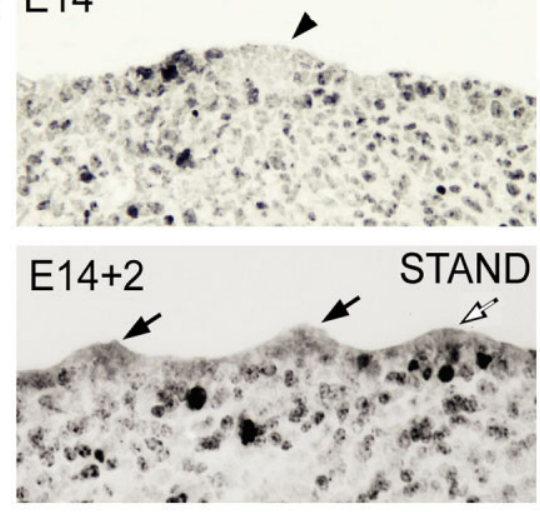

B STAND
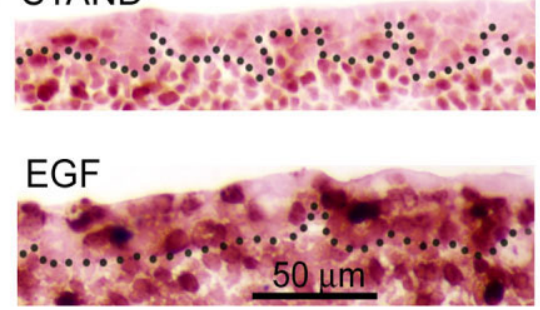
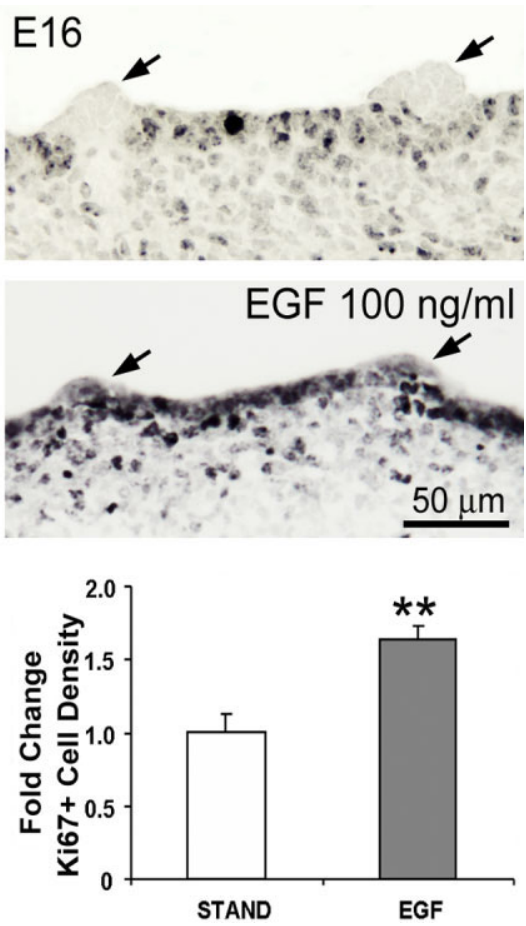

Fig. 5. Exogenous epidermal growth factor (EGF) promotes cell proliferation in inter-papilla epithelium. A: EGF and signaling in inter-papilla epithelium. Ki67-ir labels proliferating cells (black) in sagittal sections of embryonic day $(E) 14$ and $E 16$ tongue $(E 14, E 16)$ and $E 14+2$ day tongue cultures (E14+2, STAND and EGF). E14 and E16 embryo tongues: Ki67-labeled cells are absent or rare in the epithelium of prepapilla placodes ( $E 14$, arrowhead) of the $E 14$ embryo tongue, and are absent from fungiform papilla epithelium (E16, arrows) at E16. E14 + 2 day culture with STAND: As at E16, Ki67-labeled cells are more numerous between, than within papillae in $\mathrm{E} 14+2$ day tongue cultures. Arrows point to fungiform papillae and the open arrow points to a papilla sectioned through the edge, not center. E14+ 2 day culture with EGF: With added EGF at 100 ng/ml, Ki67 immunoproducts are much more numerous and dense within the expanded, inter-papilla epithelium. Arrows point to two papillae. Scale bar $=50 \mu \mathrm{m}$ for all images. B: Ki67 immunoreactions of E14 + 2 day cultures in STAND or EGF $(10 \mathrm{ng} / \mathrm{ml})$ and histogram for Ki67-positive cell density. STAND and EGF sections were together on the same slides for immunoreactions. Dotted line marks boundary between epithelium and mesenchyme. Ki67-positive cells (dark red) per area of epithelium were counted and data normalized as fold change in the histogram (means + SE). With EGF, density of Ki67+ cells was almost doubled, compared with cultures in STAND. $\left({ }^{\star \star} P<0.01\right.$, compared with STAND.)

\section{PI3K/Akt, MEK/ERK, p38 MAPK Signaling in Papilla Response to EGF}

For EGF to promote proliferation of the inter-papilla epithelium, intracellular pathways must be activated. Tyrosine kinase intracellular cascades are known to be active in EGF/EGFR signaling mechanisms and in promoting proliferation and other cell processes (Jorissen et al., 2003; Irmer et al., 2007). To study PI3K and mitogenactivated protein kinases (MAPK) in fungiform papilla responses to EGF, phosphorylated Akt, ERK1/2 and p38 MAPK first were immunolocalized and analyzed with Western blot assays in E14+2 day tongue cultures. Then specific inhibitors to PI3K/Akt,
MEK/ERK, or p38 MAPK (LY294002, U0126, or SB203580, respectively) were added to culture medium in a 1-hr incubation period, with subsequent concomitant EGF addition for up to 2 days.

In STAND cultures, phosphorylated Akt, -ERK1/2, and -p38 MAPK are present in both papilla and inter-papilla epithelium (Fig. 7A, STAND). The phosphoproteins are intense in the apical papilla epithelium (dots), and are observed also in underlying mesenchyme. When EGF is added to STAND, all three kinases are more intense throughout the epithelium (Fig. 7A, +EGF), especially in the expanded inter-papilla epithelium (regions between arrows; see for exam- 

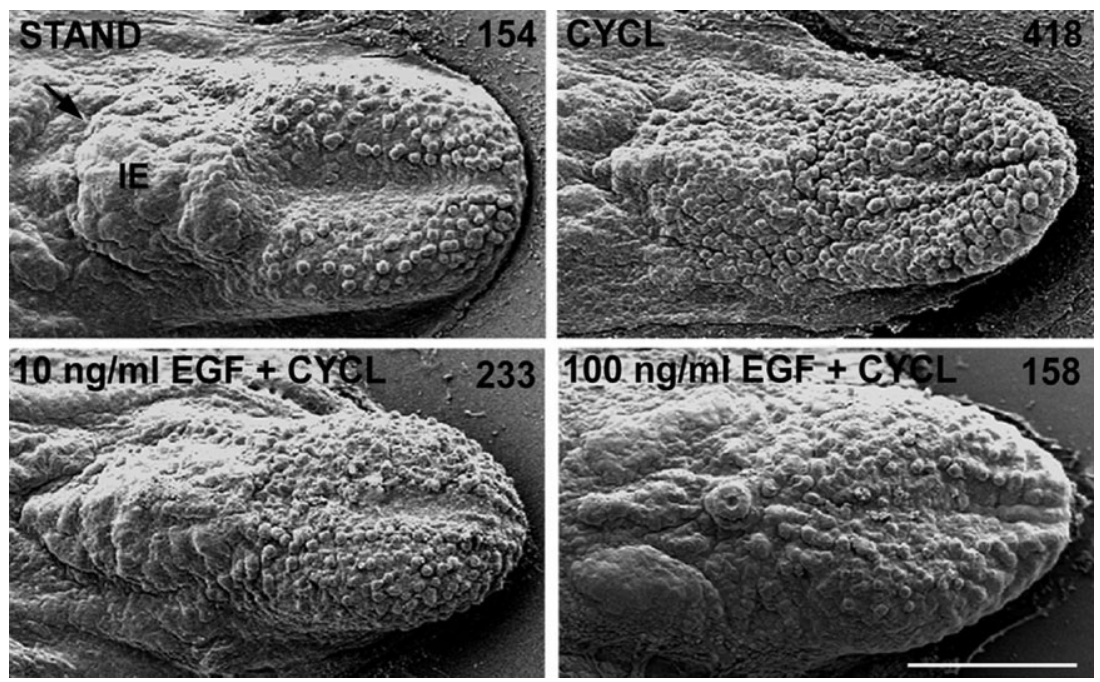

Fig. 6. Exogenous epidermal growth factor (EGF) blocks Sonic hedgehog (SHH) signal disruption effects that double numbers of fungiform papillae. Scanning electron micrographs (SEMs) of embryonic day $(E) 14+2$ day tongue cultures show that exogenous EGF prevents the increased and atypical fungiform papilla formation induced by $\mathrm{SHH}$ disruption with $5 \mu \mathrm{M}$ cyclopamine (CYCL). Tongues were cultured with STAND; with added CYCL; with CYCL plus EGF after $1 \mathrm{hr}$ preincubation with $10 \mathrm{ng} / \mathrm{ml} \mathrm{EGF}$; or with CYCL plus EGF after $1 \mathrm{hr}$ preincubation with $100 \mathrm{ng} / \mathrm{ml} \mathrm{EGF}$. Papilla numbers are indicated in the top, right corner in each image. EGF at $10 \mathrm{ng} / \mathrm{ml}$ prevented the CYCL-induced, atypical formation of fungiform papillae on the intermolar eminence (IE), while 100 $\mathrm{ng} / \mathrm{ml}$ EGF totally blocked the CYCL-induced change in fungiform papilla development and numbers (418 papillae with CYCL; 158 papillae with $100 \mathrm{ng} / \mathrm{ml}$ EGF + CYCL). An arrow points to the border of oral and pharyngeal tongue in STAND culture. Scale bar $=500 \mu \mathrm{m}$, all micrographs.

ple, phosphorylated p38 MAPK in STAND vs. +EGF).

To compare phosphorylated kinases in different conditions, we examined epithelial sheets dissociated from whole tongue cultures with Western blots. In addition, inhibition of activation for each kinase was evaluated in separate experiments with a specific inhibitor. We used an antibody that detects endogenous levels of phosphorylated ERK1/p44 MAPK and ERK2/p42 MAPK. Therefore, double bands are seen in ERK1/2 Westerns. Exogenous EGF induces a substantial increase in levels of phosphorylated Akt and ERK1/2 in the epithelium of tongue cultures without distinct alteration of total protein level (Fig. 7B). Note that this effect is apparent in epithelium from cultures with EGF in STAND and with EGF in dimethyl sulfoxide (DMSO). Furthermore, specific inhibitors to PI3K/Akt and MEK/ ERK totally block this activation (Fig. 7B, Inhibitor). Whereas levels of phosphorylated Akt could seem relatively small with EGF activation, it should be noted that small differences in activated Akt can have significant functional consequences. (Rogulski et al., 2005).
No change in phosphorylated p38 MAPK level was observed in Western blots with addition of EGF in contrast to data from immunohistochemistry experiments (Fig. 7B). Furthermore, phosphorylation of p38 MAPK was not blocked by a specific inhibitor, SB203580. In fact, though, these results are consistent with other reports indicating that SB203580 blocks activity of p38 MAPK and subsequent activation of target proteins without suppressing activation (phosphorylation) of p38 MAPK itself (Young et al., 1997; Godl et al., 2003; Morel et al., 2005).

With a direct functional assay of papilla counts, we found that the EGFdependent decrease in fungiform papilla numbers is fully reversed by inhibiting PI3K activation with LY294002, or of MEK/ERK with U0126, in a concentration-dependent manner (ANOVA $F(3,15)=15.8 ; P<$ $0.01 ; F(3,15)=22.2 ; P<0.01$ respectively; Fig. 8A,B). Inhibition of p38 MAPK with SB203580 blocks the EGF-induced decrease in papillae only at high concentration $(30 \mu \mathrm{M}$; ANOVA $F(3,23)=13.7$; Bonferroni test; $P<0.01$ ). SB202474, which is structurally similar to SB203580 but inactive in inhibiting p38 MAPK activity, does not have an effect on the EGF-induced papilla reduction. Addition of any inhibitor alone to tongue cultures does not alter fungiform papilla numbers compared with controls.

In summary, results from immunohistochemistry, Western blot analyses, and functional tests of papilla development demonstrate that components of PI3K/Akt, MEK/ERK, and p38 MAPK cascades are present and activated in embryonic tongue epithelium. Activation is increased by exogenous EGF in culture, especially in the inter-papilla epithelium. Effects on papilla number in response to EGFR stimulation are prevented by specific inhibitors, indicating that intracellular pathways include PI3K/Akt, MEK/ERK, and p38 MAPK.

\section{Synergistic Effects of MEK/ ERK With PI3K/Akt or p38 MAPK}

In the absence of $E G F$, there was no change in papilla number on inhibition of PI3K/Akt, MEK/ERK, or p38 MAPK (Fig. 8B). Furthermore, at low concentrations of inhibitors, there was no reversal of the EGF-dependent decrease in fungiform papilla numbers. These signaling cascades would predictably act in concert in the embryonic tongue, and there are additive effects among these cascades in other systems (Larsen et al., 2003; She et al., 2005), Therefore, we tested whether simultaneously blocking two or three pathways would alter papilla number.

Without exogenous EGF, combinations of $\mathrm{U}+\mathrm{SB}$, or $\mathrm{U}+\mathrm{LY}+\mathrm{SB}$, at $3 \mu \mathrm{M}$ (not effective for any one inhibitor alone to alter the number of fungiform papillae, or to alter the exogenous EGF effect), lead to an increase of approximately $25 \%$ in number of fungiform papillae, apparently blocking the role of endogenous EGF in maintaining an inter-papilla epithelium (Fig. $8 \mathrm{C}$, Graph at left; ANOVA $F(10,50)=$ 5.2; $P<0.01$; Bonferroni test; $P<$ $0.05)$.

With increased, $10 \mu \mathrm{M}$ inhibitor concentrations, $\mathrm{U}+\mathrm{LY}$ in addition to $\mathrm{U}+\mathrm{SB}$ or $\mathrm{U}+\mathrm{LY}+\mathrm{SB}$ lead to an increased number of fungiform papillae, by approximately 35\% (Fig. 8C Graph in middle; ANOVA $F(11,56)=32.5$; $P<0.01 ;$ Bonferroni test; $P<0.05$ ). 
Combined use of $\mathrm{LY}+\mathrm{SB}$, however, does not affect papilla numbers, even at $10 \mu \mathrm{M}$ concentration.

It is noteworthy that, during EGFR activation with exogenous EGF in cultures, even $3 \mu \mathrm{M}$ inhibitor concentrations are effective in demonstrating $\mathrm{U}+\mathrm{LY}, \mathrm{U}+\mathrm{SB}$ and $\mathrm{U}+\mathrm{LY}+\mathrm{SB}$ combined effects to block an EGF-induced decrease in papilla number (Fig. 8C, Graph at right; ANOVA $F(14,80)=$ 28.2; $P<0.01$; Bonferroni test; $P<$ 0.05). Again, use of $\mathrm{LY}+\mathrm{SB}$ does not block EGF effects (Fig. 8C, Graph at right). The results suggest a synergistic role of MEK/ERK with either PI3K/ Akt or p38 MAPK in regulating the EGF-mediated effect on papilla development.

\section{DISCUSSION}

The fungiform papilla is a taste organ that develops early in the embryo to provide a specialized tissue home for eventual taste bud differentiation on the anterior tongue; therefore, at some point in papilla development, taste cell progenitor epithelium resides within the papillae (Mistretta and Liu, 2006). Covering the remaining anterior tongue dorsum is the developing inter-papilla epithelium that will differentiate to form nongustatory, filiform papillae. To regulate taste papilla development and pattern, then, factors effective in emergence of the taste organ itself, and the lingual tissue between organs, must be active.

Here, we demonstrate that EGF signaling through EGFR is a key regulator of the inter-papilla epithelium and number of fungiform papillae. EGF is in early, embryonic tongue epithelium and remains distributed throughout lingual and differentiating papilla epithelium. In contrast, EGFR is progressively restricted to inter-papilla epithelium and essentially is absent from developing and advanced papillae. This restricts principal EGF action to the inter-papilla epithelium. Exogenous EGF in E13 or E14 tongue cultures regulates papilla pattern by reducing numbers of papillae, whereas inhibition of endogenous EGFR increases fungiform papilla numbers and fuses adjacent papillae, effectively eliminating an inter-papilla space. In the embryo, epithelial
A
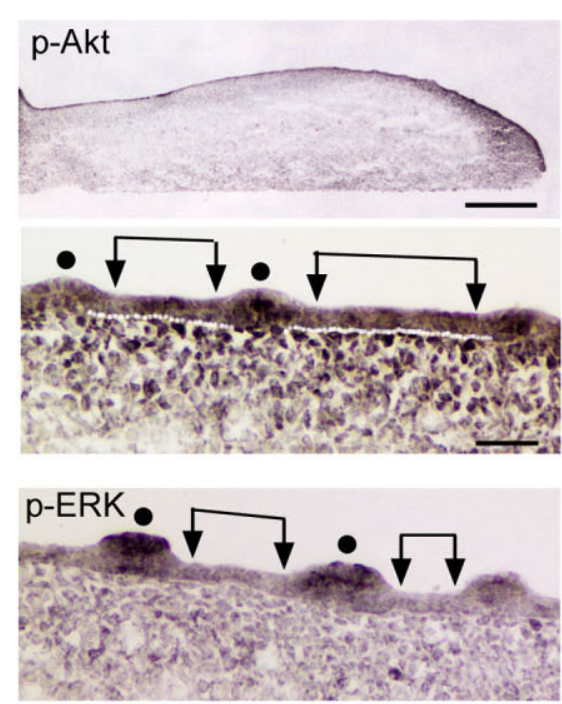

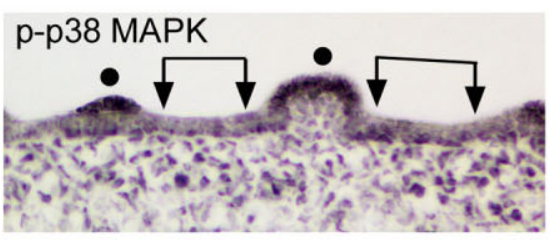

+ EGF
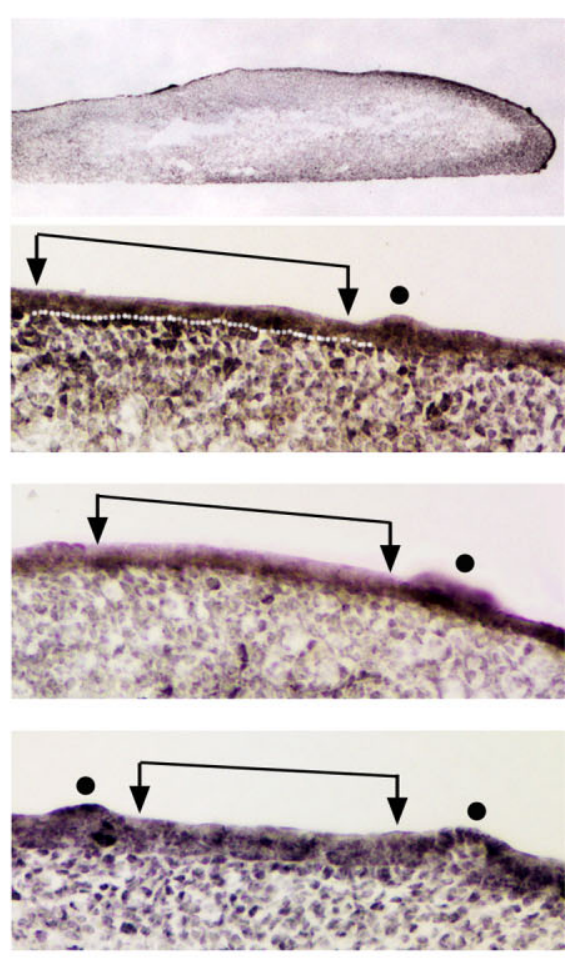

\section{B}

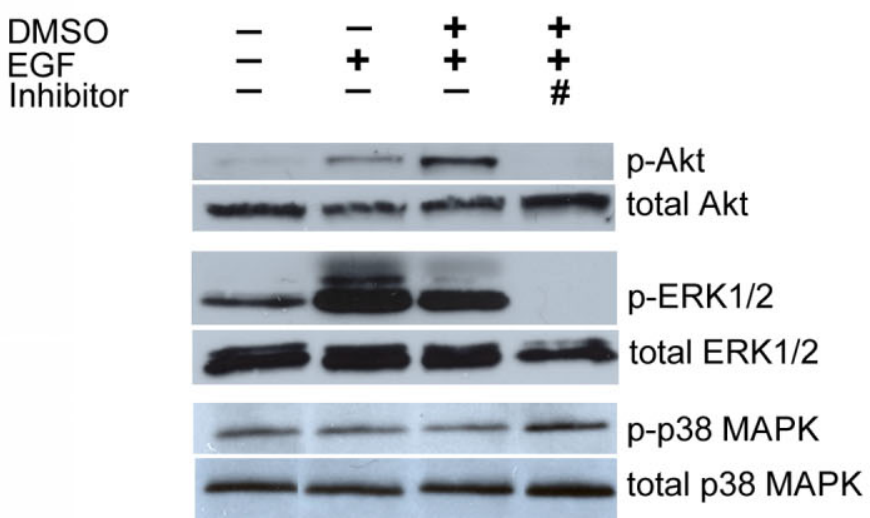

Fig. 7. Signaling by means of PI3K/Akt, MEK/ERK and $\mathrm{p} 38 \mathrm{MAPK}$ in the EGF effect on fungiform papilla number and spacing. A: Phosphorylated (p-) Akt, ERK1/2, and p38 MAPK immunoreactions in sagittal sections of E14+2 day cultures. Tongues were in standard medium (left column, STAND) or with addition of $10 \mathrm{ng} / \mathrm{ml}$ EGF (right column, +EGF). STAND and EGF culture sections were together on the same slide for immunoreactions. For $\mathrm{p}$-Akt, whole tongue sections at top illustrate clarity of immunoreactions. For p-Akt images at higher power, a white line demarcates border of epithelium from mesenchyme (STAND and +EGF). p-Akt, p-ERK, and p-p38 MAPK each is present in tongue epithelium (STAND), and is especially intense in the apical epithelium of papillae (dots). Note that immunoproducts are relatively weak in STAND inter-papilla epithelium (between arrows) compared with more intense immunoreactions with exogenous EGF (+EGF) in inter-papilla epithelium (between arrows). Scale bars $=250 \mu \mathrm{m}$ in p-Akt images (entire sections), $25 \mu \mathrm{m}$ (higher power of sections) applies to other section images. B: Western blots demonstrate the following: presence of $p-A k t, p-E R K 1 / 2$ (p- ERK1/p44 MAPK and ERK2/p42 MAPK), and p-p38 MAPK in cultured tongue epithelium dissociated from underlying mesenchyme; an increased $p$-Akt and ERK1/2 product in the presence of EGF; and, complete inhibition of activated kinase in the presence of specific inhibitors (\# = LY294002 for Akt, \# = U0126 for ERK). However, there was not an increase in p-p38 MAPK with EGF, and the specific inhibitor, SB203580 (\#), did not block activation of the kinase. Level of each of the total kinases (i.e., phosphorylated and non-phosphorylated) is not altered in experimental conditions. (\# refers to a different, specific inhibitor that was used for each kinase.) 
cell proliferation is substantially reduced in emerging papilla placodes and developing papillae, compared with the highly proliferative, inter-papilla tongue epithelium where EGFR is localized. Indeed added EGF stimulates further proliferation of inter-papilla epithelial cells in tongue cultures. EGF can block the doubling of differentiated fungiform papillae that results from disruption of SHH signaling, further indicating a bias to maintain inter-papilla epithelium. We propose that alteration of epithelial cell differentiation programs is a primary mechanism underlying EGF effects, which holds inter-papilla cells in a proliferative cycle and thereby inhibits cell differentiation programs for fungiform papilla formation. The specific effects of EGF/EGFR-mediated papilla patterning act through intracellular cascades, including PI3K/Akt, MEK/ERK, and p38 MAPK. Furthermore, interactive roles of MEK/ERK with PI3K/Akt and with p38 MAPK are apparent.

\section{EGF Signaling Through EGFR and Papilla Effects}

EGF is abundant in saliva, approximately $1 \mu \mathrm{g} / \mathrm{ml}$, which continually bathes the tongue and promotes health of oral tissues (Noguchi et al., 1991). Whereas EGF in saliva has important roles in maintaining fungiform papilla integrity in adult (Morris-Wiman et al., 2000), we found that endogenous EGF is present throughout the embryonic epithelium. In embryonic rodent, the submandibular salivary gland is functionally differentiated before birth (Hoffman et al., 2002), so exogenous EGF also is potentially available to developing oral tissues.

Although not quantified, reduced or aberrant papillae were observed in stunted tongues with thin epithelium in EGFR null mutant, postnatal surviving mice (Miettinen et al., 1995; Threadgill et al., 1995). Building on these prior studies, Sun and Oakley (2002) made a detailed study of taste bud loss in fungiform papillae in EGFR null mutants and in contrast to prior reports did not observe a reduction in papillae, but did report an un- specified number of fungiform papillae with keratinized spines. This is similar to aberrant fungiform papillae in mice with salivary gland removal (Morris-Wiman et al., 2000). Different results across studies are not unexpected because the EGFR loss-of-function phenotype is reportedly highly variable and dependent on the genetic background (Kasper et al., 2006). In sum, postnatal null mutants show that signaling through EGFR is important in maintenance of taste and nontaste papilla and tongue epithelium but provide no clear picture of EGF signaling effects in papilla formation and lingual epithelial differentiation.

EGFR belongs to a family of ErbB receptor tyrosine kinases (Harris et al., 2003; Jorissen et al., 2003): ErbB1 (the EGFR itself, HER-1), ErbB2 (Neu, or HER-2), ErbB3 (HER-3), and ErbB4 (HER-4). In rats, ErbB1-3 have been detected in adult taste bud cells in all three types of taste papillae, and also in E16-20 papillae (McLaughlin, 2000). ErbB2 individually cannot bind any known ligand and ErbB3 can only signal in a complex (Harris et al., 2003; Jorissen et al., 2003; Shilo, 2005). In the present study, we focused on EGFR, which is the receptor for EGF binding and has a stage-specific localization in interpapilla epithelium.

We identified a progressive, embryonic restriction of EGFR to inter-papilla tongue epithelium where it is intensely expressed, in contrast to distribution of EGF throughout tongue epithelium. We further demonstrated that EGF action is through EGFR. The specific distribution of EGFR in inter-papilla epithelium indicates that EGF is a spacing factor for fungiform papillae, because EGF acts to increase proliferation in epithelium that is between the papillae. In addition, developmental effects of the EGFR inhibitor, Compound 56, are to increase papilla number and fusion, in support of the conclusion that EGF/EGFR plays a physiological role in papilla patterning. In the present study we focused on EGFR, which is the receptor for EGF binding and has a specific localization in interpapilla epithelium. Although EGFR generally undergoes homodimerization (Shilo, 2005), we cannot exclude that other ErbB receptors expressed in tongue epithelium that do not act as homeodimers, form heterodimers with EGFR, for example, EGFR/ErbB2, as in skin and hair follicle development (Mak and Chan, 2003).

\section{Epithelial Cell Phenotypes of Fungiform Papillae and EGF/EGFR Function}

The early fungiform papilla forms as a placode and develops through epithelial-mesenchymal remodeling (Mistretta, 1998). Signaling in the epithelium reportedly determines position of newly formed papillae (Kim et al., 2003) and in this study our focus has been on epithelial events in particular. At papilla initiation (E14-E15, rat), epithelial cells clustered in the placode apex already are different in shape and organelle density from surrounding cells (Farbman and Mbiene, 1991). Moreover, epithelial cells in placodes and early papillae are mitotically quiescent (Farbman and Mbiene, 1991; Mbiene and Roberts, 2003; Zhou et al., 2006). In contrast, we show that the surrounding lingual epithelium is in a proliferative state (Fig. 5 ). The data suggest that placode and early papilla epithelial cells are no longer in the cell cycle, reflecting differentiation.

EGFR-activated signaling stimulates cell cycle progression, regulates cell shape and motility, and inhibits apoptosis (Woodburn, 1999; Olayioye et al., 2000; Yarden and Sliwkowski, 2001). The specific distribution of EGFR in inter-papilla tongue epithelium, where cells are proliferating, and absence of EGFR in embryonic fungiform papillae, where epithelial cells are not proliferating, suggest roles for EGFR in determining epithelial cell fate and, thus, in spacing fungiform papillae. There is a dramatic increase in cell proliferation in the inter-papilla region with addition of EGF in culture. Furthermore, EGF can block the effect of SHH signal disruption, to double the number of fungiform papillae. Together, our data support the hypothesis that EGF/EGFR activation leads to increased cell cycle progression while inhibiting differentiation to a papilla pathway; this would prevent formation of fungiform papillae and thus reduce papilla number.

From our prior studies, we know 
that the inter-papilla epithelium is competent to form fungiform papillae (Mistretta et al., 2003). Therefore, we had proposed that regulatory factors must act directly or by means of other signaling factors to suppress fungiform papilla formation and enable patterned spacing of papillae. Our current data provide strong evidence for EGF/ EGFR signaling in suppressing papilla formation in part by sustaining cell proliferation between papillae.
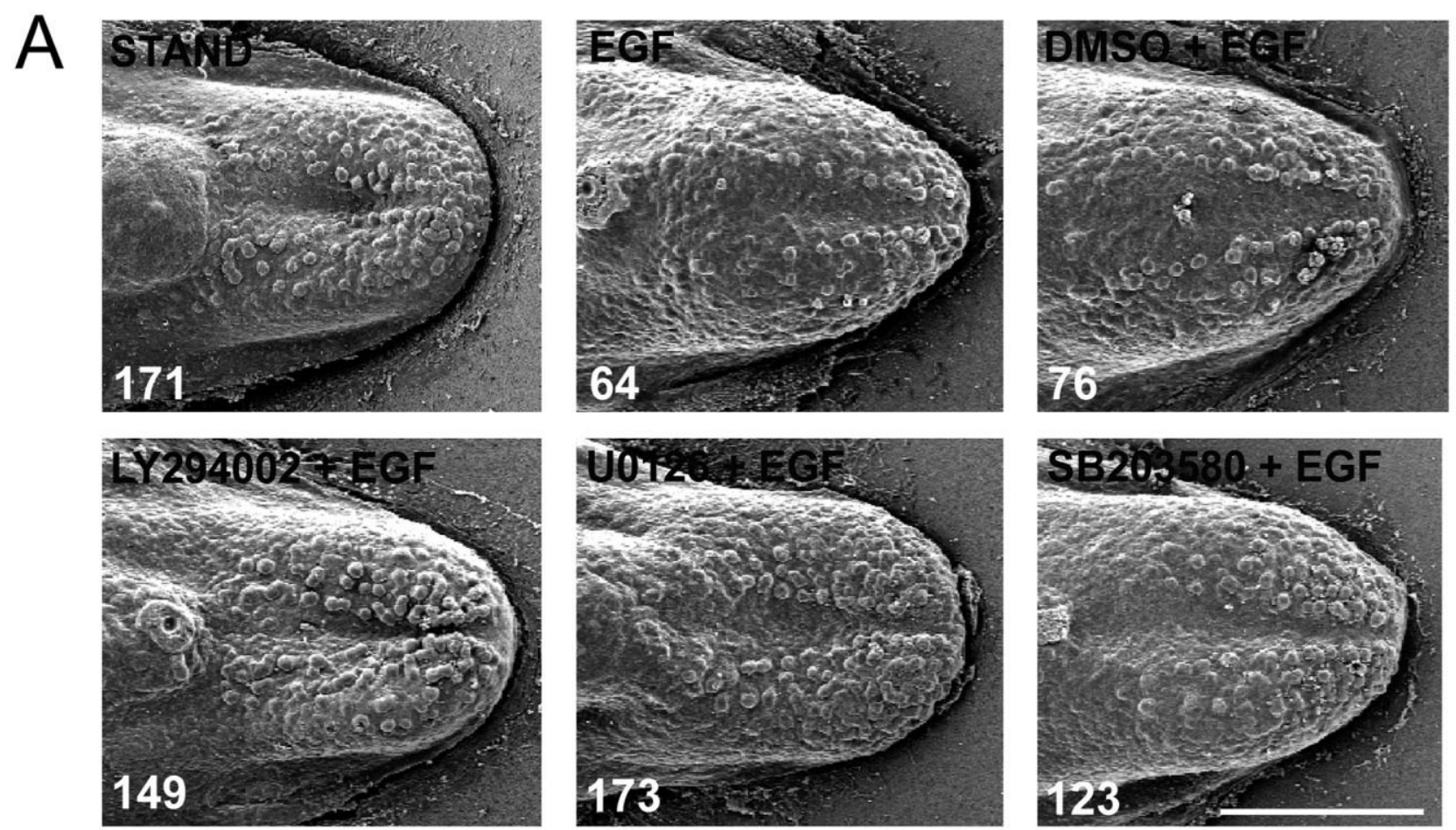

B
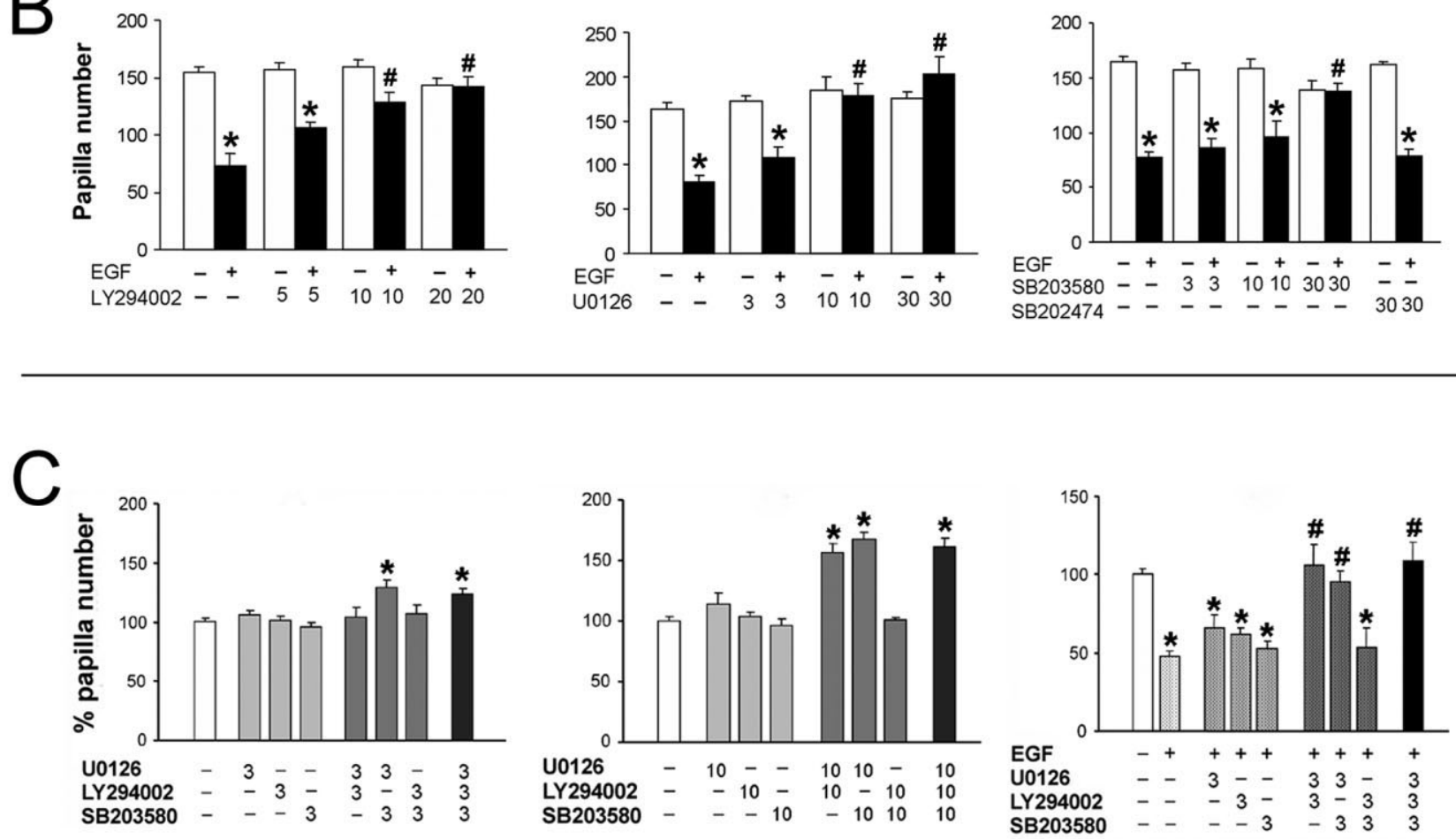

Concentration $(\mu \mathrm{M})$ of kinase inhibitors

Fig. 8. 


\section{EGF in Development of Epithelial Specializations: Feather, Hair, and Denticle}

EGF and EGFR are in chick embryo skin before feather placodes form, and then are reduced in placodes but maintained in the inter-bud epidermis (Atit et al., 2003). In culture, EGF stimulates epidermal proliferation and expands inter-bud EGFR gene expression, with a concurrent loss of feather bud gene expression. Conversely, EGFR inhibitors result in loss of inter-bud fate and lead to feather bud fusion. In hair follicles, EGFR is absent from epidermal cells over dermal condensates that mark the first stage of follicle development (Green and Couchman, 1984). EGF inhibits formation of hair buds in embryonic mouse skin culture (Kashiwagi et al., 1997). In transgenic mice that constitutively express EGF in skin, hair follicle development is retarded in postnatal animals and the epidermis is thickened (Mak and Chan, 2003). Overall, reports suggest that EGFR directs epidermal cells to an interfeather or inter-follicle fate, whereas inhibition of EGFR leads to feather or hair follicle differentiation. In Drosophila epidermis, belts of hair-like denticles alternate with smooth cuticle. Reduced EGFR signaling increases inter-denticle apoptosis and leads to fusion of adjacent denticle belts (Urban et al., 2004), indicating a conserved effect of EGF in epidermal organ formation.

Distributions and effects of EGF/ EGFR signaling in the tongue epithe- lium during papilla development are similar to those in skin and outer cuticle, during feather, hair follicle, and denticle formation. EGFR expression is in inter-papilla epithelium, and activation with EGF results in increased cell proliferation between papillae; this leads to expansion of inter-papilla space and loss of papillae. EGFR inhibition induces increased number and fusion of papillae. Our data add the taste papilla as an epithelial specialization that relies on EGF/EGFR signaling for patterning, and demonstrates common EGF/EGFR effects in developing tongue epithelium, an oral mucosa, compared with skin.

\section{Intracellular Pathways and Synergistic Roles in EGF/ EGFR Signaling}

EGF/EGFR signaling results in simultaneous activation of several intracellular pathways, which can be functionally linked (Jorissen et al., 2003). We studied PI3K/Akt, MEK/ERK, and p38 MAPK in papilla development, pathways widely associated with cell survival, proliferation, differentiation, migration, and death that are preferentially activated in response to growth factors or cell stress (Jorissen et al., 2003; Downward, 2004; Roux and Blenis, 2004).

\section{Signaling in tongue cultures.}

We detected phosphorylated Akt, ERK1/2, and p38 MAPK in lingual epithelium of nontreated E14+2 day cultures with immunohistochemistry and Western blots, suggesting active endogenous signaling in embryonic tongue. With EGF in tongue culture medium, immunoproducts of phosphorylated Akt, ERK1/2, or p38 MAPK were more intense in the epithelium compared with controls, implicating all three signaling cascades in the EGF effect on fungiform papilla development. Increased kinase intensity was especially pronounced in inter-papilla epithelium, consistent with expression of EGFR in this location.

In support of data from immunoreactions, in Western blot assays exogenous EGF effected a dramatic increase in levels of phosphorylated Akt and ERK1/2 in the epithelium of $\mathrm{E} 14+2$ day cultures. Furthermore, when a specific inhibitor for each kinase was used (LY294002 or U0126), Akt and ERK1/2 phosphorylation was completely blocked without change in total kinase level.

However, no significant change in phosphorylated p38 MAPK was observed in Western blots, in contrast to increased lingual immunoproducts of phosphorylated p38 MAPK. In addition, when SB203580 was used to block signaling through p38 MAPK, the phosphorylation of p38 MAPK was not inhibited in Western blot analysis. This is similar to reports demonstrating that SB203580 inhibits activity of p38 MAPK by blocking activation of downstream factors, but not the activation/phosphorylation of p38 MAPK itself (Godl et al., 2003; Morel et al., 2005). SB203580 inhibits $\mathrm{p} 38 \alpha$ and $\beta$ splice variants of p38 MAPK (Kumar

Fig. 8. Concentration-dependent and synergistic effects of LY294002 (PI3K/Akt inhibitor), U0126 (MEK/ERK inhibitor), and SB203580 (p38 MAPK inhibitor) on papilla development in cultures with and without epidermal growth factor (EGF). A: Inhibition of PI3K/Akt, MEK/ERK, or p38 MAPK blocked the effect of exogenous EGF on fungiform papilla development. Scanning electron micrographs (SEMs) of E14+2 day cultures with STAND; EGF; DMSO + EGF; or, EGF plus inhibitors (LY294002 for Akt, U0126 for ERK, SB203580 for p38 MAPK). Total number of papillae is shown in the bottom left corner of each image. In tongue cultures with EGF or EGF with DMSO, the number of papillae was decreased compared with STAND cultures. For inhibitor effects, tongues were incubated with LY294002, U0126, or SB203580 alone for $1 \mathrm{hr}$, followed by concurrent exposure to EGF for up to 2 days. Inhibitors for each kinase prevented the EGF-induced decrease in papilla number in tongue cultures. Scale bar $=500 \mu \mathrm{m}$ for all images. B: Histograms of papilla number (mean $+\mathrm{SE}$ ) with each inhibitor alone (blank bars) or plus EGF ( $10 \mathrm{ng} / \mathrm{ml}$; filled bars). Any inhibitor alone, from 3 to $30 \mu \mathrm{M}$, does not affect papilla number, compared with the control condition without EGF and inhibitor. However, inhibition of PI3K/Akt activation with LY294002, of MEK/ERK with U0126, or of p38 MAPK with SB203580 reverses the EGF-induced decrease in fungiform papilla numbers, in a concentrationdependent manner. SB202474 is a structural control molecule for SB203580. ( ${ }^{*} P<0.05$ compared with the group at the same concentration of inhibitor but without EGF, or filled to matched blank bar; ${ }^{\#} P<0.05$ compared with the EGF-alone group, or first filled bar.) C: Histograms of percentage of papilla number (fungiform papilla number/mean number in vehicle control group $\times 100 \%$; mean $+\mathrm{SE}$ ) at $3 \mu \mathrm{M}$ (left), or $10 \mu \mathrm{M}$ (middle) inhibitor concentrations; or with EGF addition after preincubation with inhibitor for $1 \mathrm{hr}$ (right). Without exogenous EGF, combinations of $\mathrm{U}+\mathrm{SB}$, or $\mathrm{U}+\mathrm{LY}+\mathrm{SB}$, at $3 \mu \mathrm{M}$ lead to an increase in number of papillae $\left(^{*}\right)$. Without exogenous EGF, $U+L Y, U+S B$, or $U+L Y+S B$, at $10 \mu M$, lead to an increased number of papillae, by approximately $35 \%\left(^{*}\right)$. The combined use of $\mathrm{LY}+\mathrm{SB}$, however, does not affect papilla numbers. In the presence of exogenous EGF, $3 \mu \mathrm{M}$ inhibitor concentrations are effective in blocking an EGF-induced decrease in papillae with combined use of $\mathrm{U}+\mathrm{LY}, \mathrm{U}+\mathrm{SB}$ or $\mathrm{U}+\mathrm{LY}+\mathrm{SB}$. Again, use of $\mathrm{LY}+\mathrm{SB}$ does not block EGF effects. ( ${ }^{*} P<0.05$ compared with the vehicle [DMSO] control group, white bars; ${ }^{*} P<0.05$ compared with the EGF alone group.) 
et al., 2003); p38 $\alpha$ reportedly is the most physiologically important variant, but p38 $\beta$ has suggested roles in protecting against apoptosis (Yang et al., 2004). Clearly, p38 MAPK pathways are complex and further experiments are required to understand the SB203580 inhibition of p38 MAPK activity in our tongue culture system.

\section{Functional effects and synergistic actions on papilla number.}

With inhibitors to PI3K, MEK/ERK, or p38 MAPK signaling, we found that any inhibitor alone did not alter papilla number and pattern in culture without exogenous EGF. However, with combined inhibitors, there was a dramatic increase in papilla number indicating synergistic signaling actions in endogenous papilla patterning. The MEK/ERK cascade may be a primary component in these synergies because alteration of papilla number occurred only when MEK/ERK inhibition was in conjunction with PI3K/Akt or p38 MAPK inhibition; combined use of inhibitors of the latter two kinases did not have an additive effect.

In a concentration-dependent manner, any one of the inhibitors, LY294002 for PI3K/Akt, U0126 for MEK/ERK, or SB203580 for p38 MAPK, blocked the effect of exogenous EGF in reducing fungiform papilla number. Moreover, at $3 \mu \mathrm{M}$ concentration, which is not effective alone, combined U0126 with LY294002 or SB203580 blocked the EGF-induced decrease in papilla number. Use of LY294002 with SB203580 did not block EGF effects. This further demonstrates a synergistic role of MEK/ ERK with PI3K/Akt and p38 MAPK in regulating the EGF-mediated effect on papilla pattern. Additive effects among these cascades are noted in other systems (Larsen et al., 2003; She et al., 2005). Furthermore, sensitivity to tryosine kinase inhibition is dependent on cell context and can alter with and without growth factor stimulation (Irmer et al., 2007). Therefore, differences in concentration and synergistic parameters when inhibitors are used without or with EGF stimulation are not unexpected.

While other secreted proteins might affect papilla development through

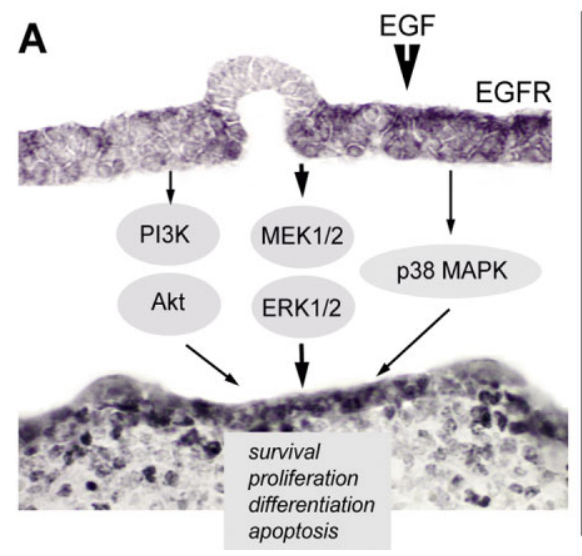

B

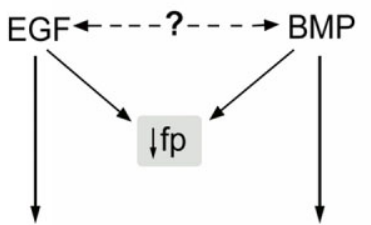

cell proliferation between fps

thin, dedifferentiated epithelium between fps

Fig. 9. Epidermal growth factor (EGF) signaling effects in inter-papilla epithelium, and model to compare EGF and bone morphogenetic protein (BMP) in fungiform papilla reduction. A: EGF signaling is progressively constrained to inter-papilla epithelium by restricted location of EGF receptor (EGFR) to inter-papilla tissue. Signaling through PI3K/Akt, MEK/ERK, and p38 MAPK cascades can interact and potentially regulate cells in the inter-papilla epithelium (for survival, proliferation, differentiation, or apoptosis), effectively biasing away from a fungiform papilla fate. B: The model indicates that both exogenous EGF (current study) and BMPs (BMP2, 4, or 7; Zhou et al., 2006b) reduce numbers of fungiform papillae in embryonic tongue. EGF signaling expands the inter-papilla space through a proliferative effect on between-papilla epithelium that biases cells away from papilla differentiation. In contrast, excess BMP effects a thinner, nonproliferative inter-papilla epithelium. Thus, whereas both EGF and BMP prevent papilla formation, different mechanisms are used. [Color figure can be viewed in the online issue, which is available at www.interscience.wiley.com.]

the PI3K/Akt and MEK/ERK and p38 MAPK signaling cascades that we have localized in developing tongue epithelium and papillae, these other potential effects have not yet been studied. We have clearly shown that exogenous EGF will not only lead to phosphorylation of these kinases, but also that when these pathways are blocked specifically, EGF no longer alters papilla number.

\section{EGF Signaling and \\ Interactions With Other Pathways in Fungiform Papilla Development}

Cell cycle progression assessed by proliferation in embryonic tongue and tongue cultures is pronounced between papilla placodes or papillae, and is virtually absent within placodes or papillae. We propose that primary effects of EGF/EGFR activation on papilla spacing and pattern are by means of signaling in the inter-papilla epithelium, through PI3K/Akt, MEK/ ERK, and p38 MAPK cascades involved in cell survival, proliferation, differentiation, migration, and/or apoptosis (Fig. 9A). If PI3K/Akt, MEK/ ERK, or p38 MAPK signaling is inhibited, more fungiform papillae form in
EGF stimulated cultures. Our data are congruent with the idea that EGFR-mediated EGF regulation of papilla number and pattern acts through signaling in the epithelium between papillae. An inter-papilla epithelial fate is promoted, rather than a papilla differentiation pathway.

In addition to EGF signaling in the inter-papilla epithelium, we previously have demonstrated that BMP2, 4, or 7 reduces formation of fungiform papillae (Zhou et al., 2006). Comparison of EGF and BMP effects in reducing papilla number is informative. In cultures with implanted beads, BMPs lead to thinning and much reduced proliferation in the tongue epithelium (Zhou et al., 2006). The BMP antagonist noggin, on the other hand, elicits formation of multiple papillae and a thicker, highly proliferative epithelium. BMP signaling effects, then, are very different from those of EGF, although both lead to reduced papillae. Whereas EGF promotes cell proliferation in inter-papilla epithelium and biases away from fungiform papilla differentiation, BMP reduces cell survival and proliferation and inhibits papilla formation (Fig. 9B). Clearly, these are factors that must be balanced in developing tongue epithelium for patterned formation of taste organs. 
Furthermore, counter to and/or interacting with EGF signaling can be stage- and concentration-specific effects of SHH (Liu et al., 2004), NOGGIN (Zhou et al., 2006), or WNT molecules (Iwatsuki et al., 2007) in papilla formation. We have shown that EGF can block $\mathrm{SHH}$ signaling effects on papilla formation. In extending our results, it will be important to determine whether, when, and how EGF, BMP, NOGGIN, SHH, and WNT signaling interact in papilla and inter-papilla epithelial formation, and how these interactions might be distinctive in accessing various intracellular tyrosine kinase cascades.

\section{EXPERIMENTAL PROCEDURES}

\section{Embryo Dissection}

Timed, pregnant Sprague-Dawley rats were from Charles River breeders. Animal maintenance and use complied with institutional animal care protocols and were according to National Institutes of Health guidelines. Morning of the day of vaginal plug detection was designated embryonic day 0 (E0). All dissections of E13E18 embryos were between 9:00 AM and 12:00 PM for consistency across litters (Mbiene et al., 1997). Pregnant dams were anesthetized with sodium pentobarbital (intraperitoneal, 60 $\mathrm{mg} / \mathrm{kg}$ body weight), also anesthetizing the embryos. Embryos were removed from the anesthetized dam and transferred to Earle's balanced salt solution with gentamicin sulfate, buffered with $20 \mathrm{mM}$ HEPES ( $\mathrm{pH}$ 7.4; Mistretta et al., 2003). Embryo heads were dissected and moved to fresh solution for cultures or rapidly frozen in O.C.T. compound (Miles Scientific, Elkhart, IN) for immunohistochemistry.

\section{Tongue Cultures}

E13 or E14 tongues were cultured for 2 days (Mbiene et al., 1997; Mistretta et al., 2003). In brief, whole tongues were dissected from the mandible and placed on sterile Millipore HA filters on stainless steel grids in culture dishes. Cultures were fed with a 1:1 mixture of Dulbecco's modified Eagle's medium and Ham's nutrient F12
(DMEM/F12, GIBCO, Gaithersburg, MD), containing $1 \%$ fetal bovine serum, $50 \mu \mathrm{g} / \mathrm{ml}$ gentamicin sulfate, and $2 \%$ B27 culture supplement (GIBCO; control or standard medium, STAND). The level of medium was adjusted so that cultures were at the gas/liquid interface, in a humidified incubator at $37^{\circ} \mathrm{C}$.

Cultures were made from E13 when the tongue epithelium has a homogenous topography and from E14 when prepapilla placodes have just begun to emerge on the tongue (Fig. 2, E13 and $\mathrm{E} 14,+0$ day). After 2 days in culture, fungiform papillae form on anterior tongue of E13 or E14 cultures (Fig. 2, E13 and E14, +2 days).

\section{Reagents}

To study roles of EGF in papilla development, human recombinant EGF (1$100 \mathrm{ng} / \mathrm{ml}$; 236-EG, R\&D Systems, Minneapolis, MN) was added to STAND. Effects of EGFR inhibition were investigated with a specific and potent inhibitor of EGFR, Compound 56 (4-[(3-Bromophenyl) amino]-6,7-diethoxyquinazoline, Calbiochem, \#234505, San Diego, CA), added to STAND, or co-administered with EGF (10 ng/ml) after $1 \mathrm{hr}$ incubation with Compound 56 alone ( $1 \mathrm{nM}-10 \mu \mathrm{M})$.

To determine intracellular pathways that mediate EGF effects, E14 cultures were incubated with specific inhibitors alone for $1 \mathrm{hr}$ followed by exposure to a mixture of EGF and inhibitor for 2 days. LY294002 (A.G. Scientific, San Diego, CA), U0126 (\#662005), and SB203580 (\#559389) (Calbiochem, San Diego, CA) were used to block PI3K, MEK1/2, and p38 MAPK, respectively. SB202474 (Calbiochem, \#559387), a structurally similar but inactive p38 MAPK antagonist, was used as a control for SB203580. A concentration range between 3 to $30 \mu \mathrm{M}$ was used for inhibitors. Cultures in STAND, or with addition of the solvent DMSO for inhibitors of EGFR and intracellular protein kinases, were used as controls.

\section{Scanning Electron Microscopy, Fungiform Papilla Quantification, and Statistics}

SEM was used to evaluate surface topography of tongues or tongue cul- tures and acquire counts of fungiform papillae in various culture conditions. Tongues or tongue cultures were fixed in $2.5 \%$ glutaraldehyde and $2 \%$ paraformaldehyde (PFA) in $0.1 \mathrm{M}$ cacodylate buffer $(\mathrm{pH} 7.3)$ at $4^{\circ} \mathrm{C}$, post-fixed in a sequence of aqueous $1 \% \mathrm{OsO}_{4}, 1 \%$ tannic acid, $1 \% \mathrm{O}_{\mathrm{S}} \mathrm{O}_{4}$, for $1 \mathrm{hr}$ each on ice, and processed as described (Mbiene et al., 1997). Tissues were mounted, sputter coated with gold/ palladium, and analyzed with SEM. Digital images were acquired and assembled using Photoshop (Adobe Systems, Mountain View, CA).

SEM images of E13 cultures at $\times 100$ and $\mathrm{E} 14$ at $\times 75$ original magnification were used to count fungiform papillae, with 5 to 13 tongues in each experimental condition. Each papilla, defined as a round or oval protuberance that has a distinctive surface epithelium from surround (Fig. 2), is marked and counted on a plastic overlay positioned over photographs of cultures.

Papilla numbers are presented as mean \pm standard error (SE). ANOVA was used for papilla quantification, followed by the Bonferroni post hoc test, at a significance level of $P<0.05$.

\section{Immunohistochemistry}

\section{Antibodies.}

Primary antibodies were as follows: EGF (\#06-102, 1:400) and EGFR (\#06129, 1:50-1:100; Upstate Biotechnology, Lake Placid NY); EGFR (\#SC-03, 1:200, Santa Cruz Biotechnology, Santa Cruz CA); Shh (\#AF464, 1:100, R\&D Systems, Minneapolis MN); Ki67 (\#NCL-Ki67p, 1:1000, Novocastro Laboratories Ltd., UK; \#M7248, 1:400, DakoCytomation, DK); p-Akt (\#9277, 1:300), p-p44/p42 MAPK or ERK1/2 (\#9101,1:250), and p-p38 MAPK (\#9211, 1:100; Cell Signaling, Beverly, MA). Slides treated with no primary antibody or with the same concentration of normal IgG were used as controls. Specificity for EGFR immunostaining was confirmed with absorption tests (primary antibody was incubated for $24 \mathrm{hr}$ with $10^{-6} \mathrm{M}$ of the immunogen EGFR, before adding to tissue sections). 


\section{Whole tongue}

immunohistochemistry.

To localize EGFR in embryo tongues or Shh in tongue cultures, tongues were fixed in $4 \%$ PFA in $0.1 \mathrm{M}$ phosphate buffered saline (PBS), $\mathrm{pH} 7.4$, at $4^{\circ} \mathrm{C}$ for $2 \mathrm{hr}$, and processed as described (Liu et al., 2004).

\section{Tissue section}

\section{immunohistochemistry.}

To immunolocalize EGF, EGFR, and phosphorylated -Akt, -ERK1/2, or -p38 MAPK, dissected embryo heads or tongue cultures were frozen in O.C.T. Serial sagittal sections were cut at 12 $\mu \mathrm{m}$, thaw-mounted onto gelatin coated slides and fixed at $4^{\circ} \mathrm{C}$ for 1.5 $\mathrm{hr}$ in $4 \% \mathrm{PFA}$ in 0.1 M PBS, pH 7.4. After fixation, sections were reacted as described (Mistretta et al., 2003; Liu et al., 2004).

\section{Ki67-Postive Cell Quantification}

Ki67 antigen is normally expressed in nuclei of cells in all phases of the cell cycle, and not in G0. We used Ki67 antibody to label proliferating cells. To quantify Ki67+ cells in STAND and EGF cultures, serial sagittal sections were cut and sections from STAND and EGF cultures mounted on the same slides for immunoreactions. A set of five to six nonconsecutive sections (midway between the lateral border and median furrow of the tongue culture) was captured with light microscopy and subsequently viewed on screen, from STAND or EGF cultures. For each captured section, the basement membrane region was outlined and a $150 \mu \mathrm{m}$ length of tongue epithelium that did not include fungiform papillae was marked. Each Ki67+ cell in the marked length of epithelium that had a clearly labeled nucleus was designated with a dot and the section was photographed and printed. Then, Ki67+ cells (dots) were counted in each photographed section. For intensely labeled sections, often seen with exogenous EGF, we crosschecked slides under the light microscope with on-screen images to be certain that Ki67+ cells were accurately marked with a dot. Inserting dots onscreen allowed repeated viewing of magnified images to optimize accurate identification of Ki67+ cells. To derive a measure of Ki67+ cells per area of epithelium, total cell counts were divided by area measurement $(150 \mu \mathrm{m}$ length of tongue epithelium $\times$ measured depth of epithelium from basement membrane to surface, in $\mu \mathrm{m}$ ). Data were normalized to cell counts in STAND, to express a fold change in cell density with exogenous EGF.

\section{Western Blots}

Total and phosphorylated Akt, ERK1/2, and p38 MAPK were detected with Western blot assays. $\mathrm{E} 14+2$ day cultures were divided into four groups (12 cultures/group) for each protein kinase: standard medium, STAND; EGF (10 ng/ml); $\mathrm{EGF}+\mathrm{DMSO}$; and, EGF+kinase inhibitor $(20 \mu \mathrm{M}$ LY294002, $10 \mu \mathrm{M}$ U0126, or $30 \mu \mathrm{M}$ SB203580). After 2 days in culture, tongues were incubated with dispase II (2.4 unit/ml, Gibco, Germany) added to the original culture medium for $30 \mathrm{~min}$ at $37^{\circ} \mathrm{C}$. The epithelial sheet was peeled from mesenchyme and transferred to $0.2 \%$ Nonidet-P40 lysis buffer containing protease and phosphatase inhibitors on ice for $10 \mathrm{~min}$. The epithelial lysate was centrifuged and the supernatant collected. Protein content in the supernatant was determined with the Bio-Rad protein assay (Hercules, CA). Equal amounts of protein were run with sodium dodecyl sulfate-polyacrylamide gel electrophoresis and transferred to nitrocellulose membrane. Procedures for blocking and antibody probing were as described (Mitra et al., 2003). Visualization of immunoreactive proteins was accomplished by the chemiluminescence system (Pierce, Rockford, IL) and exposure to film.

\section{ACKNOWLEDGMENTS}

We thank Dr. Cathy Krull for discussion and comments on the manuscript. C.M.M. was funded by a Grant from the National Institute on Deafness and Other Communication Disorders, NIH (DC000456).

\section{REFERENCES}

Atit R, Conlon RA, Niswander L. 2003. EGF signaling patterns the feather ar- ray by promoting the interbud fate. Dev Cell 4:231-240.

Bridges AJ, Zhou H, Cody DR, Rewcastle GW, McMichael A, Showalter HD, Fry DW, Kraker AJ, Denny WA. 1996. Tyrosine kinase inhibitors. 8. An unusually steep structure-activity relationship for analogues of 4-(3-bromoanilino)-6,7-dimethoxyquinazoline (PD 153035), a potent inhibitor of the epidermal growth factor receptor. J Med Chem 39:267-276.

Downward J. 2004. PI 3-kinase, Akt and cell survival. Semin Cell Dev Biol 15: 177-182.

Farbman AI, Mbiene JP. 1991. Early development and innervation of taste budbearing papillae on the rat tongue. J Comp Neurol 304:172-186.

Godl K, Wissing J, Kurtenbach A, Habenberger P, Blencke S, Gutbrod H, Salassidis K, Stein-Gerlach M, Missio A, Cotton M, Daub H. 2003. An efficient proteomics method to identify the cellular targets of protein kinase inhibitors. Proc Natl Acad Sci U S A 100:15434-15439.

Green MR, Couchman JR. 1984. Distribution of epidermal growth factor receptors in rat tissues during embryonic skin development, hair formation, and the adult hair growth cycle. J Invest Dermatol 83: 118-123.

Hall JM, Bell ML, Finger TE. 2003. Disruption of sonic hedgehog signaling alters growth and patterning of lingual taste papillae. Dev Biol 255:263-277.

Harris RC, Chung E, Coffey RJ. 2003. EGF receptor ligands. Exp Cell Res 284:2-13.

Hill DL. 2001. Taste development. In: Blass E, editor. Handbook of behavioral neurobiology, developmental psychobiology. Vol. 13. New York: Plenum. p 517549.

Hoffman MP, Kidder BL, Steinberg ZL, Lakhani S, Ho S, Kleinman HK, Larsen M. 2002. Gene expression profiles of mouse submandibular gland development: FGFR1 regulates branching morphogenesis in vitro through BMP- and FGFdependent mechanisms. Development 129:5767-5778.

Irmer D, Funk JO, Blaukat A. 2007. EGFR kinase domain mutations - functional impact and relevance for lung cancer therapy. Oncogene 26:5693-5701.

Iwatsuki K, Liu HX, Grunder A, Singer MA, Lane TF, Grosschedl R, Mistretta C, Margolskee RF. 2007. Wnt signaling interacts with Shh to regulate taste papilla development. Proc Natl Acad Sci U S A 104:2253-2258.

Jorissen RN, Walker FW, Pouliot N, Garrett TPJ, Ward CW, Burgess AW. 2003. Epidermal growth factor receptor: mechanisms of activation and signaling. Exp Cell Res 284:31-53.

Kashiwagi M, Kuroki T, Huh N. 1997. Specific inhibition of hair follicle formation by epidermal growth factor in an organ culture of developing mouse skin. Dev Biol 189:22-32.

Kasper M, Schnidar H, Neill GW, Hanneder M, Klingler S, Blaas L, Schmid C, Hauser-Kronberger C, Regl G, Philpott MP, Aberger F. 2006. Selective 
modulation of Hedgehog/GLI target gene expression by epidermal growth factor signaling in human keratinocytes. Mol Cell Biol 26:6283-6298.

Kaufman MH. 1992. Atlas of mouse development. San Diego: Academic Press. p 422-423.

Kim JY, Mochizuki T, Akita K, Jung HS. 2003. Morphological evidence of the importance of epithelial tissue during mouse tongue development. Exp Cell Res 290:217-226.

Kumar S, Boehm J, Lee JC. 2003. p38 MAP kinases: key signalling molecules as therapeutic targets for inflammatory diseases. Nat Rev Drug Discov 2:717-726.

Larsen M, Hoffman MP, Sakai T, Neibaur JC, Mitchell JM, Yamada KM. 2003. Role of PI3-kinase and PIP3 in submandibular gland branching morphogenesis. Dev Biol 255:178-191.

Liu HX, MacCallum DK, Edwards C, Gaffield W, Mistretta CM. 2004. Sonic hedgehog exerts distinct, stage-specific effects on tongue and taste papilla development. Dev Biol 276:280-300.

Liu F, Thirumangalathu S, Gallant NM, Yang SH, Stoick-Cooper CL, Reddy ST, Andl T, Taketo MM, Dlugosz AA, Moon RT, Barlow LA, Millar SE. 2007. Wntbeta-catenin signaling initiates taste papilla development. Nat Genet 39:106112.

Mak KK, Chan SY. 2003. Epidermal growth factor as a biologic switch in hair growth cycle. J Biol Chem 278:2612026126.

Mbiene JP, Roberts JD. 2003. Distribution of keratin 8-containing cell clusters in mouse embryonic tongue: evidence for a prepattern for taste bud development. J Comp Neurol 457:111-122.

Mbiene JP, MacCallum DK, Mistretta CM. 1997. Organ cultures of embryonic rat tongue support tongue and gustatory papilla morphogenesis in vitro without intact sensory ganglia. J Comp Neurol 377 : 324-340.

McLaughlin SK. 2000. Erb and c-Kit receptors have distinctive patterns of expression in adult and developing taste papillae and taste buds. J Neurosci 20:5679 5688 .

Miettinen PJ, Berger JE, Meneses J, Phung Y, Pedersen RA, Werb Z, Derynck R. 1995. Epithelial immaturity and multiorgan failure in mice lacking epidermal growth factor receptor. Nature 376:337341.

Mistretta CM. 1972. Topographical and histological study of the developing rat tongue, palate, and taste buds. In: Bosma JF, editor. The third symposium on oral sensation and perception: the mouth of the infant. Springfield: Thomas. p 163-187.

Mistretta CM. 1991. Developmental neurobiology of taste. In: Getchell T, Doty R, Bartoshuk L, Snow J, editors. Smell and taste in health and disease. New York: Raven Press. p 35-64.

Mistretta CM. 1998. The role of innervation in induction and differentiation of taste organs: introduction and background. Ann N Y Acad Sci 855:1-13.

Mistretta CM, Liu HX. 2006. Development of fungiform papillae: patterned lingual gustatory organs. Arch Histol Cytol 69: 199-208.

Mistretta CM, Liu HX, Gaffield W, MacCallum DK. 2003. Cyclopamine and jervine in embryonic rat tongue cultures demonstrate a role for Shh signaling in taste papilla development and patterning: fungiform papillae double in number and form in novel locations in dorsal lingual epithelium. Dev Biol 253:450-468.

Mitra RS, Zhang Z, Henson BS, Kurnit DM, Carey TE, D'Silva NJ. 2003. Rap1A and rap1B ras-family proteins are prominently expressed in the nucleus of squamous carcinomas: nuclear translocation of GTP-bound active form. Oncogene 22: 6243-6256.

Morel C, Ibarz G, Oiry C, Carnazzi E, Berge G, Gagne D, Galleyrand JC, Martinez J. 2005. Cross-interactions of two p38 mitogen-activated protein (MAP) kinase inhibitors and two cholecystokinin (CCK) receptor antagonists with the CCK1 receptor and p38 MAP kinase. J Biol Chem 280:21384-21393.

Morris-Wiman J, Sego R, Brinkley L, Dolce C. 2000. The effects of sialoadenectormy and exogenous EGF on taste bud morphology and maintenance. Chem Senses 25:9-19.

Noguchi S, Ohba Y, Oka T. 1991. Effect of salivary epidermal growth factor on wound healing of tongue in mice. Am J Physiol 260:E620-E625.

Nosrat CA, MacCallum DK, Mistretta CM. 2001. Distinctive spatiotemporal expression patterns for neurotrophins develop in gustatory papillae and lingual tissues in embryonic tongue organ cultures. Cell Tissue Res 203:35-45.

Okubo T, Pevny LH, Hogan BLM. 2006. Sox2 is required for development of taste bud sensory cells. Genes Dev 20:26542659.

Olayioye MA, Neve RM, Lane HA, Hynes NE. 2000. The ErbB signaling network: receptor heterodimerization in development and cancer. EMBO J 19:3159-3167.
Rogulski K, Li Y, Rothermund K, Pu L Watkins S, Yi F, Prochownik EV. 2005. Onzin, a c-Myc-repressed target, promotes survival and transformation by modulating the Akt-Mdm2-p53 pathway. Oncogene 24:7524-7541.

Roux PP, Blenis J. 2004. ERK and p38 MAPK-activated protein kinases: a family of protein kinases with diverse biological functions. Microbiol Mol Biol Rev 68: $320-344$.

She QB, Solit DB, Ye Q, O'Reilly KE, Lobo J, Rosen N. 2005. The BAD protein integrates survival signaling by EGFR/ MAPK and PI3K/Akt kinase pathways in PTEN-deficient tumor cells. Cancer Cell 8:287-297.

Shilo BZ. 2005. Regulating the dynamics of EGF receptor signaling in space and time. Development 132:4017-4027.

Sun H, Oakley B. 2002. Development of anterior gustatory epithelia in the palate and tongue requires epidermal growth factor receptor. Dev Biol 242:31-43.

Threadgill DW, Dlugosz AA, Hansen LA, Tennenbaum T, Lichti U, Yee D, LaMantia C, Mourton T, Herrup K, Harris RC, Barnard JA, Yuspa SH, Coffey RJ, Magnuson T. 1995. Target disruption of mouse EGF receptor: effect of genetic background on mutant phenotype. Science 269:230-234.

Urban S, Brown G, Freeman M. 2004. EGF receptor signalling protects smooth-cuticle cells from apoptosis during Drosoph ila ventral epidermis development. Development 131:1835-1845.

Woodburn JR. 1999. The epidermal growth factor receptor and its inhibition in cancer therapy. Pharmacol Ther 82:241-250.

Yang B, Cao DJ, Sainz I, Colman RW, Guo YL. 2004. Different roles of ERK and p38 MAP kinases during tube formation from endothelial cells cultured in 3-dimensional collagen matrices. J Cell Physiol 200:360-369.

Yarden Y, Sliwkowski MX. 2001. Untangling the ErbB signalling network. Nat Rev Mol Cell Biol 2:127-137.

Young PR, McLaughlin MM, Kumar S, Kassis S, Doyle ML, McNulty D, Gallagher TF, Fisher S, McDonnell PC, Carr SA, Huddleston MJ, Seibel G, Porter TG, Livi GP, Adams JL, Lee JC. 1997. Pyridinyl imidazole inhibitors of p38 mitogen-activated protein kinase bind in the ATP site. J Biol Chem 272:12116-12121.

Zhou Y, Liu HX, Mistretta CM. 2006. Bone morphogenetic proteins and noggin: inhibiting and inducing fungiform papilla development. Dev Biol 297:198-213. 